\title{
Article \\ Performance Evaluation of Solar Energy Cells Using the Interval-Valued T-Spherical Fuzzy Bonferroni Mean Operators
}

\author{
Maria Akram ${ }^{1}$, Kifayat Ullah ${ }^{1}\left(\mathbb{D}\right.$ and Dragan Pamucar ${ }^{2, *}$ (i) \\ 1 Department of Mathematics, Riphah International University, Lahore Campus, Lahore 54000, Pakistan; \\ akrammaria11@gmail.com (M.A.); kifayat.khan.dr@gmail.com (K.U.) \\ 2 Department of Logistics, Military Academy, University of Defense in Belgrade, 11000 Belgrade, Serbia \\ * Correspondence: dragan.pamucar@va.mod.gov.rs; Tel.: +381-113603188
}

check for updates

Citation: Akram, M.; Ullah, K.; Pamucar, D. Performance Evaluation of Solar Energy Cells Using the Interval-Valued T-Spherical Fuzzy Bonferroni Mean Operators. Energies 2022, 15, 292. https://doi.org/ $10.3390 /$ en15010292

Academic Editor: George Philippidis

Received: 11 December 2021 Accepted: 30 December 2021 Published: 1 January 2022

Publisher's Note: MDPI stays neutral with regard to jurisdictional claims in published maps and institutional affiliations.

Copyright: (C) 2022 by the authors. Licensee MDPI, Basel, Switzerland. This article is an open access article distributed under the terms and conditions of the Creative Commons Attribution (CC BY) license (https:// creativecommons.org/licenses/by/ $4.0 /)$.

\begin{abstract}
To find the correspondence between every number of attributes, the Bonferroni mean (BM) operator is most widely used and proven to be a flexible approach. To express uncertain information, the frame of the interval-valued T-spherical fuzzy set (IVTSFS) is a recent development in fuzzy settings which discusses four aspects of uncertain information using closed sub-intervals of $[0,1]$ and hence reduces the information loss greatly. In this research study, we introduced the principle of BM operators with IVTSFS to develop the principle of the inter-valued T-spherical fuzzy (IVTSF) BM (IVTSFBM) operator, the IVTSF-weighted BM (IVTSFWBM) operator, the IVTSF geometric BM (IVTSFGBM) operator, and the IVTSF-weighted geometric BM (IVTSFWGBM) operator. To see the significance of the proposed BM operators, we applied these BM operators to evaluate the performance of solar cells that play an important role in the field of energy storage. To do so, we developed a multi-attribute group decision-making (MAGDM) procedure based on IVTSF information and applied it to the problem of solar cells to evaluate their performance under uncertainty, where four aspects of opinion about solar cells were taken into consideration. We studied the results obtained using BM operators with some previous operators to see the significance of the proposed IVTSF BM operators.
\end{abstract}

Keywords: T-spherical fuzzy sets; interval-valued T-spherical fuzzy sets; Bonferroni mean operators; multi-attribute group decision-making

\section{Introduction}

The theory of a fuzzy set (FS) was proposed by Zadeh [1] in 1965, where he defined the degree of membership (DM) limited to $[0,1]$. FS is a very powerful tool to solve (MAGDM) multi-attribute decision-making and MAGDM problems. FS may not solve some complex problems, for instance, when an individual faces information in the shape of yes or no. To solve that kind of information, Atanassov [2] explored the theory of an intuitionistic fuzzy set (IFS), which is the expansion of FS to deal with indistinct data in daily life problems. In IFSs, $u_{\bar{\tau}}$ denotes the DM and $v_{\bar{\tau}}$ denotes the degree of non-membership (DNM) that makes a pair of the form $\left(u_{\bar{\imath}}, v_{\bar{\imath}}\right)$ such that $u_{\bar{\imath}}+v_{\bar{\imath}} \in[0,1]$. The most important feature of IFS is that the sum of the duplet is less than or equal to 1 , i.e., $u_{\bar{\imath}}+v_{\bar{\imath}} \leq 1$. Current work on IFS can be discovered in [3-5] to see the impact of IFSs. Occasionally, we take some pair of numbers randomly, such as $(0.3,0.9)$, for which $0.3+0.9=1.2$, which exceeds 1 . To cope with this kind of issue and to handle such information, Yager [6] introduced the structure of Pythagorean FS (PyFS). A PyFS permits the sum of the squares of the duplet between 0 and 1 , i.e., $u^{2}+v^{2} \leq[0,1]$. Hence the pair of numbers $(0.3,0.9)$ can be classified as a Pythagorean fuzzy number $(\mathrm{PyFN})$ because $\left(0.3^{2}+0.9^{2}\right)=0.9 \leq 1$. Yager increased the range for assigning the duplet by introducing the notion of PyFS. On the theory of PyFS, some current work may be viewed in [7-10]. Similarly, IFS and PyFS also face relevant problems in assigning the duplet independently. Yager [11] generalized the notion of IFS 
and PyFS to q-rung orthopair FS (qROFS), in which the sum of the qth-power of the duplet lies between 0 to 1 using the variable parameter $\mathfrak{q} \in \mathbb{Z}^{+}$, i.e., $u^{\mathfrak{q}}+v^{\mathfrak{q}} \leq 1$. If we choose information 0.7 as DM and 0.8 as DNM, we have $(0.7,0.8)$. Then, such a duplet cannot be classified as intuitionistic fuzzy or Pythagorean fuzzy but can be considered as a q-rung orthopair fuzzy number ( $q R O F N$ ) by fixing $\mathfrak{q}=3$. Some current work may be viewed in [12-16].

To cope with uncertainty or inconsistency, the frame of IFS seems to be a limited version, for example, in the scenario of voting when an expert provides data in the shape of yes, abstinence, no, and refusal. To survive that kind of situation, the principle of a picture fuzzy set (PFS) was presented by Cuong [17], which deals with three-dimensional information using a degree of abstinence (DA) and degree of refusal (DR), along with DM and DNM. The well-known PFS has a strict condition on the DM, DNM, and DA, which states that the sum of all three must be less than or equal to 1 . Countless studies on PFSs have been conducted involving a diverse range of applications which can be seen in [18-21]. After some time, it was realized that the theory of PFS is not valid in numerous situations as it was difficult to determine accurate information because of strict limitations on the DM, DA, and DNM, for instance, when the information is in the form of $(0.5,0.3,0.4)$, such as $0.5+0.3+0.4=1.2 \notin[0,1]$. Due to this drawback of PFS, Mahmood et al. [22] introduced the theory of a spherical fuzzy set (SFS) that provides enlargement in the range for assigning the DM, DA, and DNM from $[0,1]$ with the condition that $u^{2}+\bar{\imath}^{2}+v^{2} \in[0,1]$, which is more reliable and flexible than the frame of PFS. The notion of SFS noticeably expanded the space of PFS but still the domain of the SFS is restricted to cope with some kinds of situations. Mahmood et al. [22] generalized the idea of SFS by introducing the concept of T-spherical fuzzy (TSFS), which was completely flexible for the allocation of the DM, DNM, and DA with no limitation at all. For a triplet $(0.9,0.5,0.8)$, for which $0.9+0.5+0.8=2.2 \notin[0,1]$ and $0.9^{2}+0.5^{2}+0.8^{2}=1.7 \notin[0,1]$, such triplets cannot be specified in the layout spherical fuzzy or picture fuzzy settings. To make the information of the type $(0.9,0.5,0.8)$ applicable, we have $\mathfrak{q}=4$ in the frame of TSFSs, for which $0.9^{\mathfrak{q}}+0.5^{\mathfrak{q}}+0.6^{\mathfrak{q}}=0.462 \in[0,1]$. Therefore, TSFS is the most generalized structure of FS theory that can be applied to various situations. Studies on the aggregation operators (AOs) of TSFSs can be found in [23-28], while the study of the information measures of TSFSs may be seen in [29-31]. Particular studies on the TSF graphs and TSF soft sets can be seen in [32,33].

There exist numerous kinds of AOs to aggregate the data; however, certain AOs or no one interrelates the input information. To find the interrelationship of the input arguments, Yager [34] developed the power average operator and Liu and Yu [35] presented some density AOs which consider the density weights of the attributes. To efficiently consider the relationship of the aggregated information, Bonferroni [36] presented the idea of BMOs and the Heronian mean operator (HMO) introduced by Sykora [37]. In IFSs, the idea of BMOs was widely studied by $\mathrm{Xu}$ and Yager [38], where DM, DA, and DNM are used to express the BMOs. Liang et al. [39] enhanced the idea of BMOs by enlarging its range by defining it for Pythagorean fuzzy information. The concept of BMOs was further strengthened by Liu and Liu [40] by giving them flexibility for allocation. Some BMOs are presented by Ates and Akay [41], in which DM, DNM, and DA are used along with the frame of PFSs. Regarding BMOs, some beneficial work may be shown in [42-49].

Keeping in mind the discussion of the above paragraph, BMOs take account of the interrelationship between the input information with larger flexibility, unlike averaging AOs [23], Einstein AOs [27], power AOs [34], and density AOs [35], under uncertainty. Moreover, the BMOs based on the duplets of IFSs, PyFSs, qROFSs, and GBMO describe uncertain information using a DM and DNM only and hence information loss is likely to occur [45-49]. These structures of IFSs and PyFSs have also a limitation in allocating the duplets due to their strict nature. Furthermore, the BMOs discussed in the frames of PFSs and SFSs [41-44] also fail in providing independence for assigning the DM, DNM, and DA under uncertain conditions. Ullah et al. [50,51] suggested that expressing the uncertain 
knowledge by means of an interval instead of crisp numbers leads us to reliable results and proposed the novel notion of IVTSFS. This significance can be seen numerically in [50]. By keeping all these factors in mind, as well as the broad approach of IVTSFS proposed by Ullah et al. [50,51], the aim of this research study is to develop the concepts of BMOs in the layout of IVTSFSs, where the uncertain information is expressed using a DM, DNM, $\mathrm{DA}$, and DR in the form of closed sub-intervals of $[0,1]$, with greater flexibility and hence significantly decreased chances for information loss.

The application of fuzzy MAGDM in the field of energy is eminent and several studies have been established in this regard. For sustainable energy planning, Riaz et al. [52] used the notion of the Einstein AOs of qROFSs. Dhiman and Deb [53] used TOPSIS and CORPAS methods to study their applications in hybrid wind farms. Another interesting approach in the field of energies is the site selection of the solar photovoltaic power plant using two-stage decision making by Wang et al. [54]. Wang et al. [55] also studied the performance evaluation of the solar photovoltaic plants using three-stage decision-making algorithms. Riaz et al. studied the plastic recycling phenomena using cubic bipolar fuzzy information. The problem of the workplace charging station is comprehensively discussed by Erdogan et al. [56]. Our goal of the presented BM operators is to apply them in MAGDM problems in the field of solar energy, where the selection of the most reliable solar cells is carried out using a comprehensive numerical example.

The remainder of the paper is organized as follows. In Section 1, we briefly introduce the research background as well as the aims and objectives of the proposed work. In Section 2, the concept of IVTSFNs, their operational laws, and BMOs are briefly described. We develop the idea of the IVTSFBM, IVTSFWBM, IVTSFGBM, and IVTSFWGBM operator in Section 3. All the listed BMOs are shown with examples. In Section 4, we develop a method of MAGDM techniques to find the reliability and capability of the investigated operators in a practical way by using the proposed TSF BMOs. In Section 5, we enlarge the effect of the present work by establishing a comparative study of the new work with previously defined AOs. In Section 6, we end this paper with some concluding remarks.

\section{Preliminaries}

In this section, we study the idea of IVTSFNs and recall their operational laws. Here, we also elaborate on the idea of IVBMO.

Definition 1([24]). For any set X, IVTSFS is of the form $A=\left\{x,\left(\left[u_{A}^{l}(x), u_{A}^{u}(x)\right],\left[\bar{l}_{A}^{l}(x), \bar{\imath}_{A}^{u}(x)\right]\right.\right.$, $\left.\left.\left[v_{A}^{l}(x), v_{A}^{u}(x)\right]\right): x \in X\right\}$, where $\left[u_{A}^{l}(x), u_{A}^{u}(x)\right],\left[\bar{l}_{A}^{l}(x), \bar{\imath}_{A}^{u}(x)\right]$ and $\left[v_{A}^{l}(x), v_{A}^{u}(x)\right]$ express the DM, DA, and DNM with $0 \leq u_{A}^{u^{\mathfrak{q}}}(x)+\left[\bar{l}_{A}^{l^{q}}(x), \bar{\imath}_{A}^{u^{\mathfrak{q}}}(x)\right]+\left[v_{A}^{l^{q}}(x), v_{A}^{u^{\mathfrak{q}}}(x)\right] \leq 1, \mathfrak{q} \in \mathbb{Z}^{+}$. The DR is expressed as $\pi_{A}(x)=\left[\left(1-\left(u_{A}^{u^{\mathfrak{q}}}(x)+\bar{\imath}_{A}^{u^{\mathfrak{q}}}(x)+v_{A}^{u^{\mathfrak{q}}}(x)\right)\right)^{\frac{1}{\mathfrak{q}}},\left(1-\left(u_{A}^{l^{\mathfrak{q}}}(x)+\bar{\imath}_{A}^{l^{\mathfrak{q}}}(x)\right.\right.\right.$ $\left.\left.\left.+v_{A}^{l \mathfrak{q}}(x)\right)\right) \frac{1}{\mathfrak{q}}\right]$. We define the triplet $\mathrm{a}=\left(\left[u_{A}^{l}(x), u_{A}^{u}(x)\right],\left[\tilde{l}_{A}^{l}(x), \bar{\imath}_{A}^{u}(x)\right],\left[v_{A}^{l}(x), v_{A}^{u}(x)\right]\right)$ as an IVTSF number (IVTSFN).

Definition 2 ([24]). For IVTSFNs $\tilde{\mathrm{a}}_{1}=\left(\left[u_{1}^{l}, u_{1}^{u}\right],\left[\overline{\mathrm{l}}_{1}^{l},,_{1}^{u}\right],\left[v_{1}^{l}, v_{1}^{u}\right]\right), \tilde{\mathrm{a}}_{2}=\left(\left[u_{2}^{l}, u_{2}^{u}\right],\left[\bar{l}_{2}^{l}, \bar{l}_{2}^{u}\right]\right.$, $\left.\left[v_{2}^{l}, v_{2}^{u}\right]\right)$, then

$$
\begin{aligned}
& \tilde{\mathrm{a}}_{1} \leq \tilde{\mathrm{a}}_{2} \text { iff } u_{1}^{l} \leq u_{2}^{l}, u_{1}^{u} \leq u_{2}^{u}, \overline{\mathrm{\imath}}_{1}^{l} \geq \overline{\mathrm{\imath}}_{2}^{l}, \overline{\mathrm{\imath}}_{1}^{u} \geq \overline{\mathrm{\imath}}_{2}^{u}, v_{1}^{l} \geq v_{2}^{l}, v_{1}^{u} \geq v_{2}^{u} \\
& \tilde{\mathbf{a}}_{1} \bigcup \tilde{\mathbf{a}}_{2}=\left(\left[u_{1}^{l} \vee u_{2}^{l}, u_{1}^{u} \vee u_{2}^{u}\right],\left[\bar{l}_{1}^{l} \wedge \overline{\mathbf{l}}_{2}^{l}, \bar{\iota}_{1}^{u} \wedge \overline{\mathbf{l}}_{2}^{u}\right],\left[v_{1}^{l} \wedge v_{2}^{l}, v_{1}^{u} \wedge v_{2}^{u}\right]\right) \\
& \tilde{\mathbf{a}}_{1} \bigcap \tilde{\mathbf{a}}_{2}=\left(\begin{array}{c}
{\left[u_{1}^{l} \wedge u_{2}^{l}, u_{1}^{u} \wedge u_{2}^{u}\right],\left[\bar{\imath}_{1}^{l} \vee \bar{\imath}_{2}^{l}, \bar{\iota}_{1}^{u} \vee \bar{\imath}_{2}^{u}\right],} \\
{\left[v_{1}^{l} \vee v_{2}^{l}, v_{1}^{u} \vee v_{2}^{u}\right]}
\end{array}\right)
\end{aligned}
$$




$$
\begin{aligned}
& \tilde{\mathbf{a}}_{1} \oplus \tilde{\mathbf{a}}_{2}=\left(\begin{array}{c}
{\left[\left(u_{1}^{l^{q}}+u_{2}^{l^{q}}-u_{1}^{l^{\mathfrak{q}}} u_{2}^{l^{q}}\right)^{\frac{1}{q}},\left(u_{1}^{u^{\mathfrak{q}}}+u_{2}^{u^{\mathfrak{q}}}-u_{1}^{u^{\mathfrak{q}}} u_{2}^{u^{\mathfrak{q}}}\right)^{\frac{1}{\mathfrak{q}}}\right]} \\
{\left[\bar{\imath}_{1}^{l} \cdot \bar{\imath}_{2}^{l}, \bar{\imath}_{1}^{u} \cdot \bar{\imath}_{2}^{u}\right],\left[v_{1}^{l} \cdot v_{1}^{u}, v_{2}^{l} \cdot v_{2}^{u}\right]}
\end{array}\right)
\end{aligned}
$$

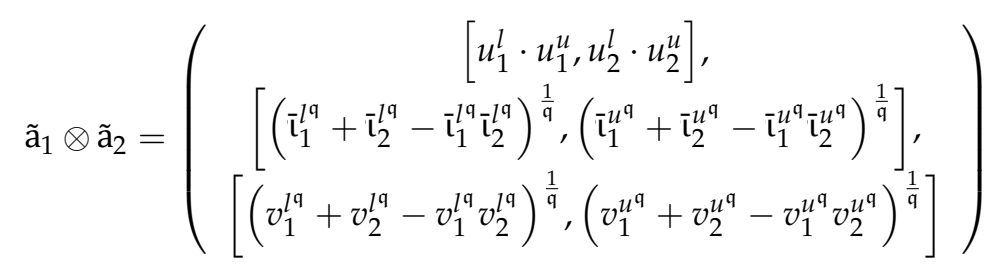

$$
\begin{aligned}
& \lambda \tilde{\mathrm{a}}_{1}=\left(\left[\left(1-\left(1-u_{1}^{l^{\mathfrak{q}}}\right)^{\lambda}\right)^{\frac{1}{\mathfrak{q}}},\left(1-\left(1-u_{1}^{u^{\mathfrak{q}}}\right)^{\lambda}\right)^{\frac{1}{\mathfrak{q}}}\right],\left[\bar{l}_{1}^{\lambda^{\lambda}}, \bar{u}_{1}^{u^{\lambda}}\right],\left[v_{1}^{l^{\lambda}}, v_{1}^{l^{\lambda}}\right]\right), \lambda>0 \\
& \tilde{\mathrm{a}}_{1}^{\lambda}=\left(\begin{array}{c}
{\left[u_{1}^{l^{\lambda}}, u_{1}^{u^{\lambda}}\right],\left[\left(1-\left(1-\bar{\imath}_{1}^{l^{\mathfrak{q}}}\right)^{\lambda}\right)^{\frac{1}{q}},\left(1-\left(1-\overline{\mathrm{l}}_{1}^{\mathcal{q}^{\mathfrak{q}}}\right)^{\lambda}\right)^{\frac{1}{q}}\right],} \\
{\left[\left(1-\left(1-v_{1}^{l^{q}}\right)^{\lambda}\right)^{\frac{1}{q}},\left(1-\left(1-v_{1}^{u^{\mathfrak{q}}}\right)^{\lambda}\right)^{\frac{1}{q}}\right]}
\end{array}\right)
\end{aligned}
$$

Definition 3 ([24]). For IVTSFN $\tilde{\mathbf{a}}=\left(\left[u_{\tilde{\mathrm{a}}}^{l}(x), u_{\tilde{\mathbf{a}}}^{u}(x)\right],\left[\bar{l}_{\tilde{\mathbf{a}}}^{l}(x), \bar{\tau}_{\tilde{\mathbf{a}}}^{u}(x)\right],\left[v_{\tilde{\mathbf{a}}}^{l}(x), v_{\tilde{\mathbf{a}}}^{u}(x)\right]\right)$, a score function is defined by:

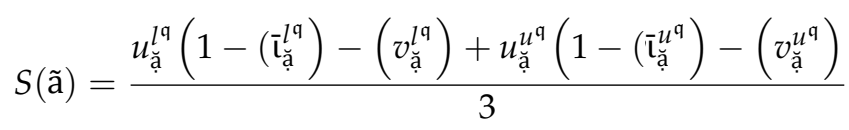

where $s, t \geq 0$.

Definition 4 ([51]). For any positive numbers $\tilde{\mathrm{a}}_{k}(k=1,2, \ldots, m)$ with $s, t \geq 0$, the BMO is demonstrated by:

$$
B M^{s, t}\left(\tilde{\mathbf{a}}_{1}, \tilde{\mathrm{a}}_{2}, \ldots, \tilde{\mathbf{a}}_{m}\right)=\left(\frac{1}{m(m-1)} \sum_{\substack{\boldsymbol{\imath}, j=1 \\ \bar{\imath} \neq j}}^{m} \tilde{\mathbf{a}}_{\overline{\mathrm{l}}}^{\tilde{\mathbf{a}}_{J}^{t}}\right)^{\frac{1}{s+t}}
$$

Definition 5 ([49]). For any positive numbers $\tilde{a}_{k}(k=1,2, \ldots, m)$ with $s, t \geq 0$, the GBM operators is demonstrated by:

$$
B M^{s, t}\left(\tilde{\mathbf{a}}_{1}, \tilde{\mathbf{a}}_{2}, \ldots, \tilde{\mathbf{a}}_{m}\right)=\frac{1}{s+t}\left(\prod_{\substack{\mathbf{\imath}, j=1 \\ \bar{\imath} \neq j}}^{m}\left(s \tilde{\mathbf{a}}_{\overline{\mathbf{\imath}}}+t \tilde{\mathbf{a}}_{j}\right)\right)^{\frac{1}{m(m-1)}}
$$

\section{Bonferroni Mean Operators for IVTSFSs}

Certain individuals have utilized the theory of BMO in the fields of IFS, PyFS, qROFS, and PFS., but no one has utilized it in the field of IVTSFS. The major contribution of this study is to combine the technique of BMO and IVTSFS to initiate the principle of the 
IVTSFBM operator, IVTSFWBM operator, IVTSFGBM operator, and IVTSFWGBM operator. By using the explored operators, many specific cases and important results are developed.

Definition 6 ([24]). For any set X, an IVTSFN is in the form of $\tilde{\mathrm{a}}_{k}=\left(\left[{\breve{a^{l}}}_{k^{\prime}} \stackrel{\vec{a}}{u}_{k}^{u}\right],\left[\hat{c}_{k}^{l}, \dot{c}_{k}^{u}\right],\left[\dot{\mathrm{b}}_{k}^{l}, \dot{\mathrm{b}}_{k}^{u}\right]\right)$, $(k=1,2, \ldots, \mathrm{m})$, with $s, t \geq 0, \mathfrak{q} \in \mathbb{Z}^{+}$. The IVTSFBM operator is a map IVTSFBM $: \Omega^{\mathrm{m}} \rightarrow \Omega$ and defined as:

$$
\operatorname{IVTSFBM}^{s, t}\left(\tilde{\mathrm{a}}_{1}, \tilde{\mathrm{a}}_{2}, \ldots, \tilde{\mathrm{a}}_{\mathrm{m}}\right)=\left(\frac{1}{\left.\mathrm{~m}_{(\mathrm{m}}-1\right)} \oplus_{\substack{\mathrm{m}, \overline{\mathrm{l}}=1 \\ \overline{\mathrm{i}} \neq \mathrm{j}}}^{\mathrm{m}}\left(\tilde{\mathrm{a}}_{\overline{\mathrm{l}}}^{s} \otimes_{D} \tilde{\mathrm{a}}_{J}^{t}\right)\right)^{\frac{1}{s+t}}
$$

By using Definition 6 and Definition 2, we obtained the following result.

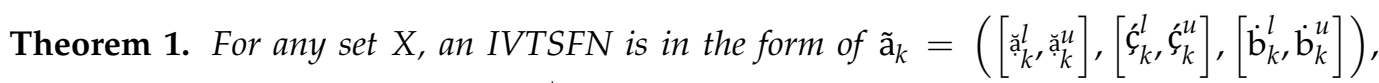
$\left(k=1,2, \ldots, \mathrm{m}_{3}\right)$ with $s, t \geq 0, \mathfrak{q} \in \mathbb{Z}^{+}$and we have:

$$
\begin{aligned}
& \operatorname{IVTSFBM} M^{s, t}\left(\tilde{a}_{1}, \tilde{a}_{2}, \ldots, \tilde{a}_{m}\right)
\end{aligned}
$$

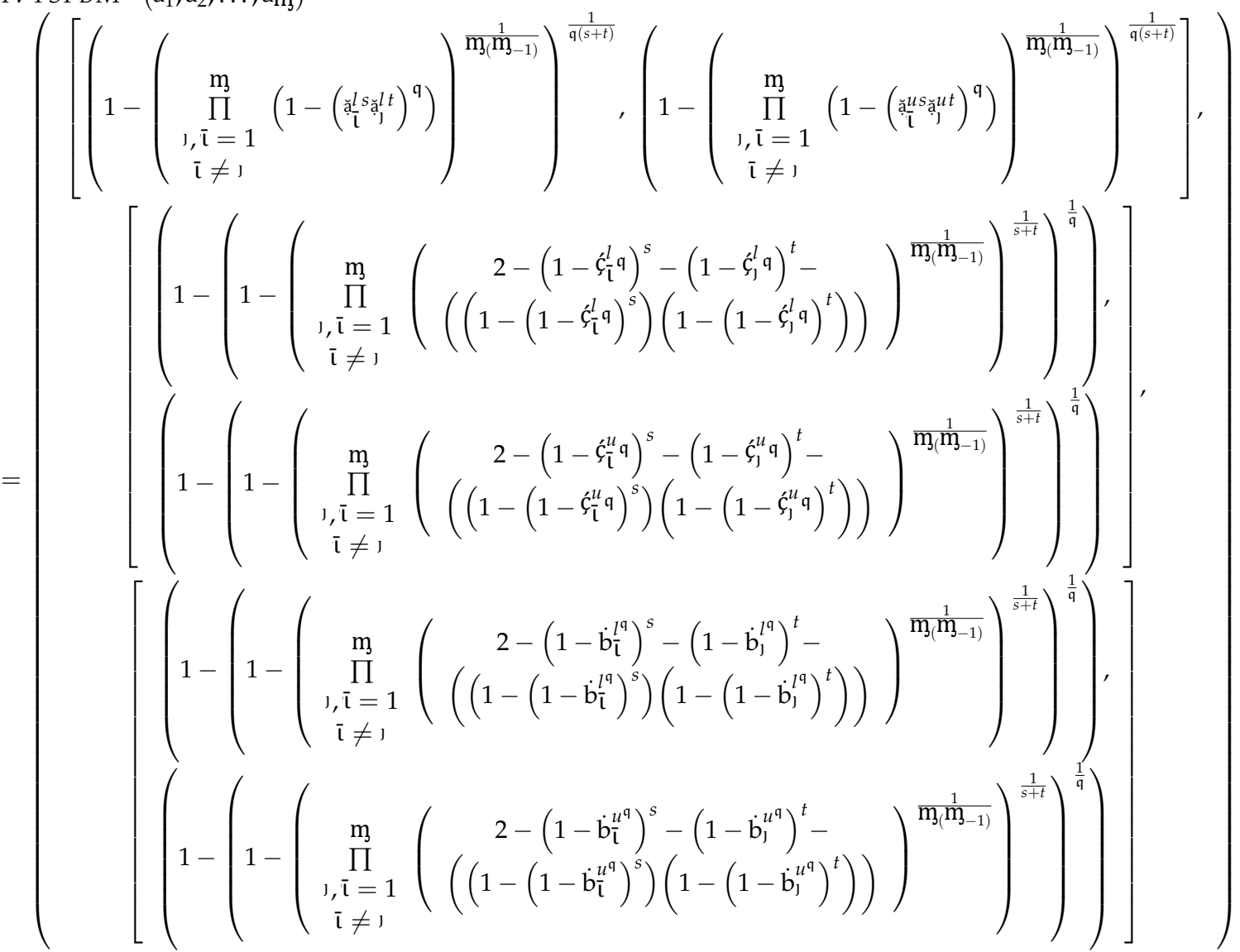

Proof. By using Equation (6), we have

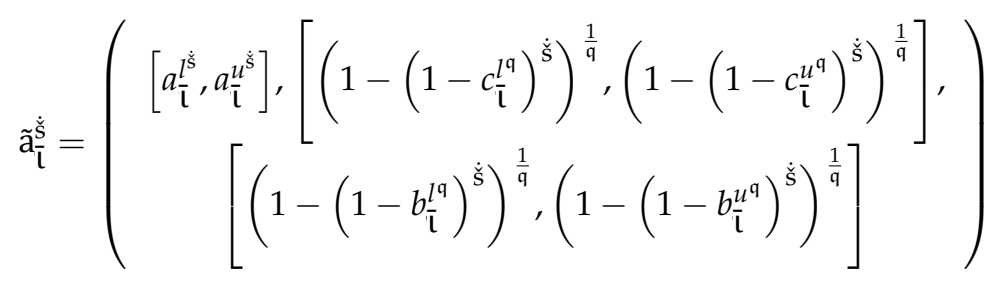




$$
\tilde{\mathrm{a}}_{j}^{t}=\left(\begin{array}{c}
{\left[a_{j}^{l^{t}}, a_{j}^{u^{t}}\right],\left[\left(1-\left(1-c_{j}^{l^{q}}\right)^{\natural}\right)^{\frac{1}{q}},\left(1-\left(1-c_{j}^{u^{q}}\right)^{\natural}\right)^{\frac{1}{q}}\right],} \\
{\left[\left(1-\left(1-b_{j}^{l^{q}}\right)^{\natural}\right)^{\frac{1}{q}},\left(1-\left(1-b_{j}^{u^{q}}\right)^{\natural}\right)^{\frac{1}{q}}\right]}
\end{array}\right)
$$

By using Equation (4), we derive:

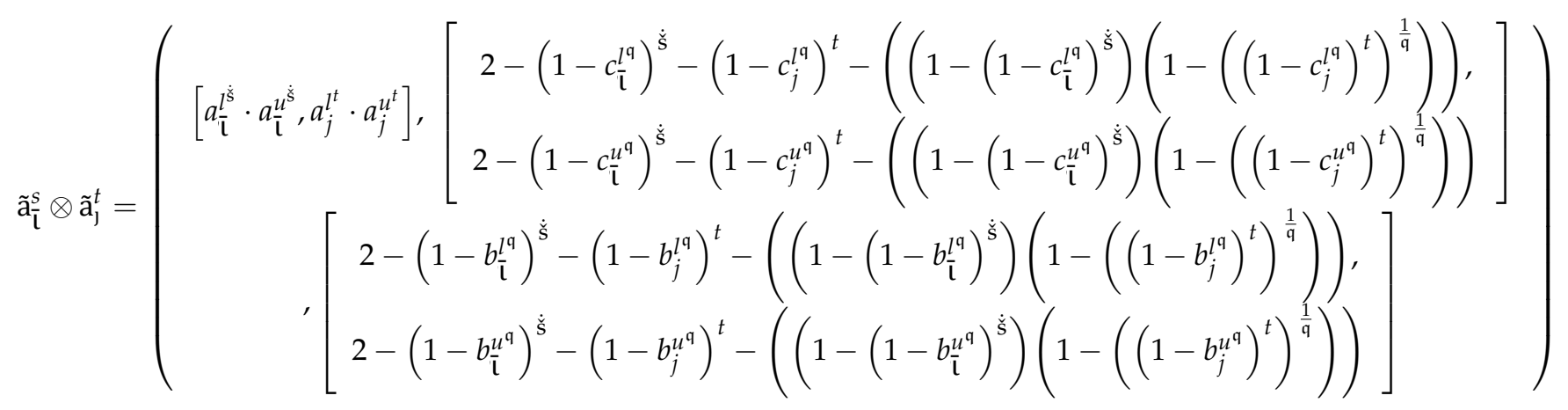

By using Equation (5), we have:

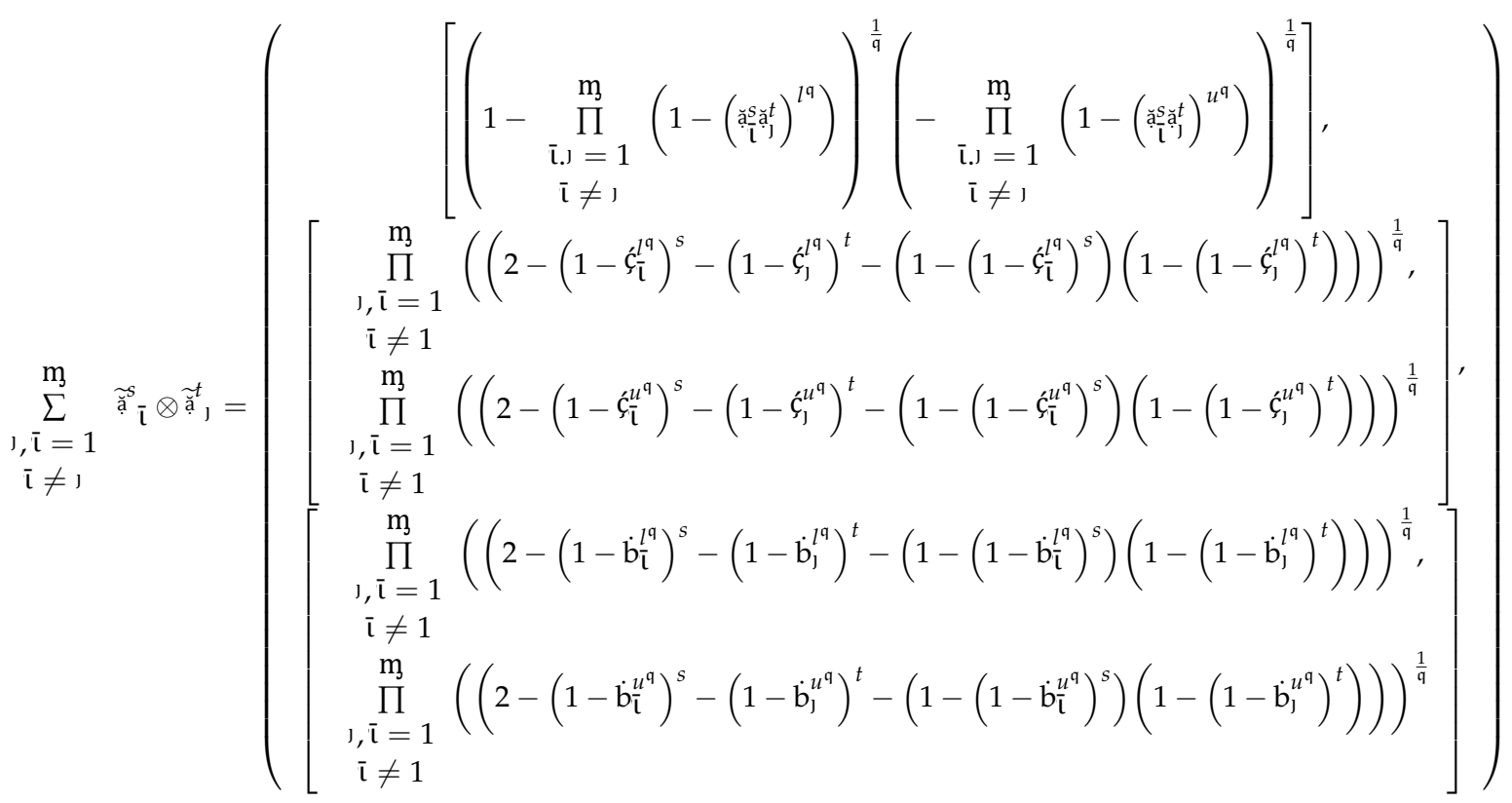

Furthermore, 


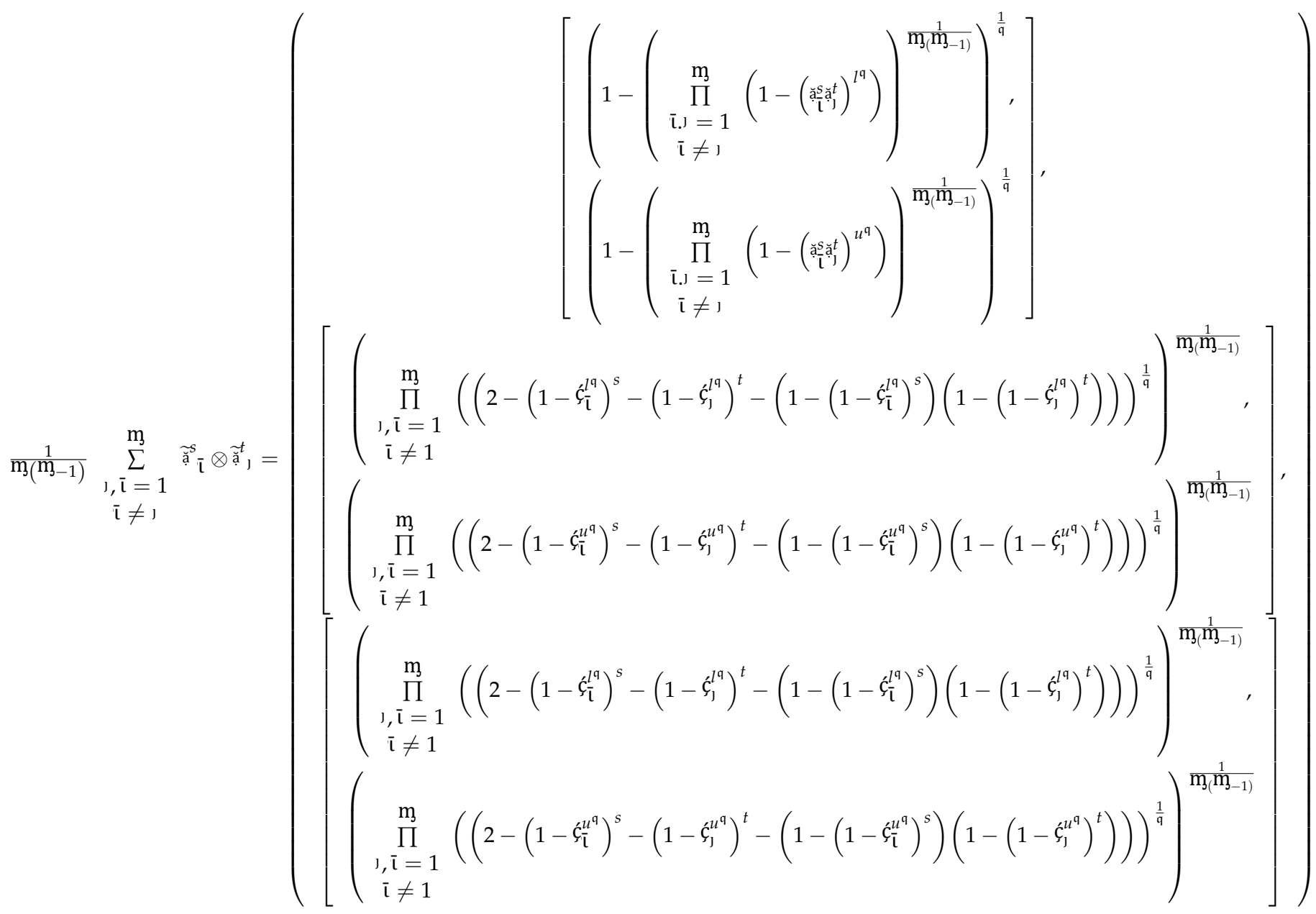

Furthermore, idempotency, monotonicity, and boundedness are desirable properties of the IVTSFBM.

Theorem 2. For any set $X$, let $\left\{\tilde{a}_{1}, \tilde{a}_{2}, \ldots, \tilde{a}_{m}\right\}$ be a collection of IVTSFNs. If all $\tilde{a}_{k},(k=1,2, \ldots, \mathrm{m})$ are equal, that is, $\tilde{\mathrm{a}}_{k}=\tilde{\mathrm{a}}=\left[\tilde{\mathrm{a}}^{l}, \tilde{\mathrm{a}}^{u}\right],\left[\dot{c}^{l}, \dot{c}^{u}\right],\left[\dot{\mathrm{b}}^{l}, \dot{\mathrm{b}}^{u}\right]$, then $s, t \geq 0, \mathfrak{q} \in \mathbb{Z}^{+}$. Then,

$$
\operatorname{IVTSFBM} M^{s, t}\left(\tilde{\mathrm{a}}_{1}, \tilde{\mathrm{a}}_{2}, \ldots, \tilde{\mathrm{a}}_{\mathrm{m}}\right)=\tilde{\mathrm{a}}
$$

Proof . Let IVTSFBM ${ }^{s, t}\left(a_{1}, a_{2}, \ldots, a_{\mathrm{m}}\right)=\left[u_{a}^{l}(x), u_{a}^{u}(x)\right],\left[i_{a}^{l}(x), i_{a}^{u}(x)\right],\left[v_{a}^{l}(x), v_{a}^{u}(x)\right]=$ $(u, i, v)$.

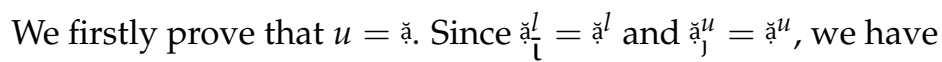




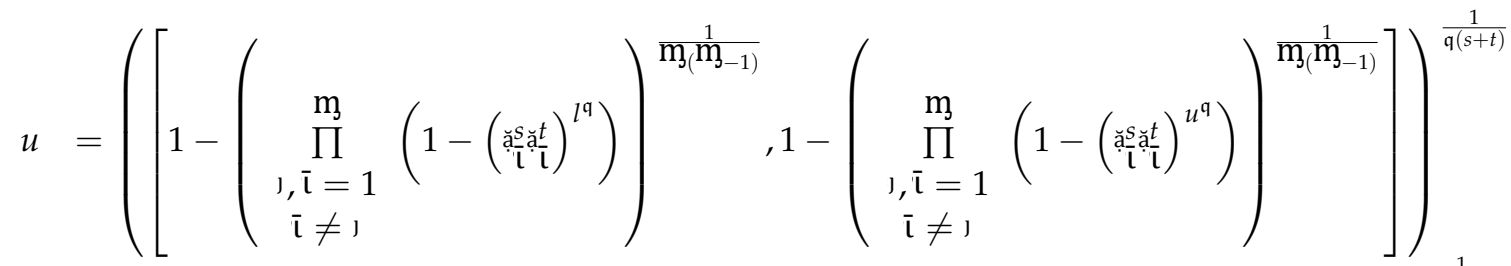

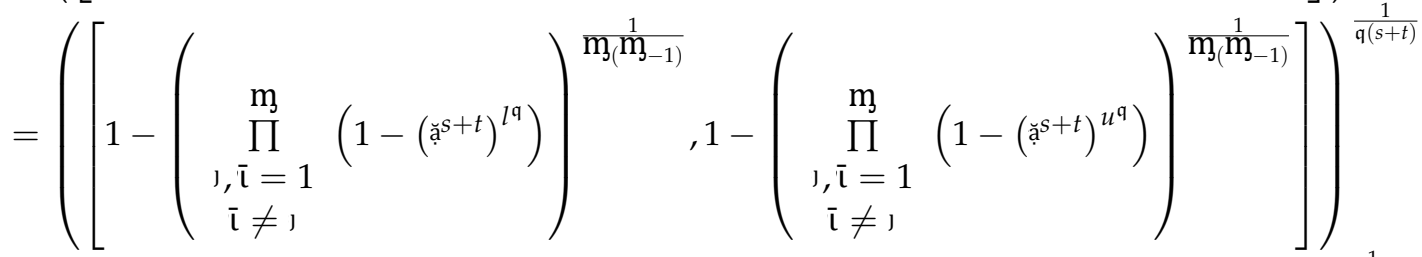

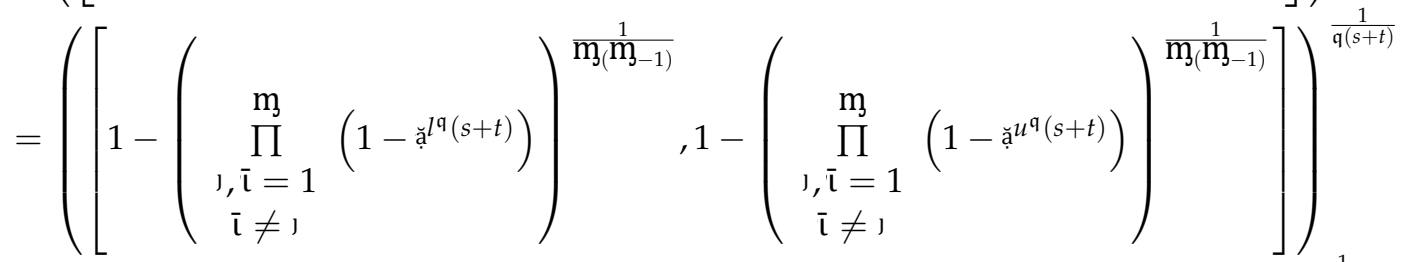

$$
\begin{aligned}
& =\left(\left[1-\left(\left(1-\breve{a ̆ g}^{l \mathfrak{q}(s+t)}\right)^{m_{\left.\left(m_{-1}\right)\right)}}\right)^{\frac{1}{m_{3}\left(m_{-1)}\right.}}, 1-\left(\left(1-\breve{a ̆ g}^{u^{\mathfrak{q}}(s+t)}\right)^{m_{(} m_{-1))}}\right)^{\frac{1}{m_{(} m_{-1)}}}\right]\right)^{\frac{1}{\mathfrak{q}(s+t)}} \\
& =\left(\left[1-1+\breve{a ̣ a ~}^{q^{\mathfrak{q}}(s+t)}, 1-1+\breve{a ̆}^{\mathfrak{q}(s+t)}\right]\right)^{\frac{1}{\mathfrak{q}(s+t)}}=\stackrel{a}{a}
\end{aligned}
$$

That is, $u=\stackrel{a}{\text {. }}$.

1. We can also prove that $i=c ̧$

2. We can also prove that $v=\dot{\mathrm{b}}$

Thus, we have $(u, \bar{l}, v)=\left(\left[a^{l}, a^{u}\right],\left[\hat{c}^{l}, \dot{c}^{u}\right],\left[\dot{\mathrm{b}}^{l}, \dot{\mathrm{b}}^{u}\right]\right)$, that is, IVTSFBM $M^{s, t}$ $\left(a_{1}, a_{2}, \ldots, a_{\mathrm{m}}\right)=a$.

Theorem 3. For any set $X$, let $\tilde{\mathrm{a}}_{k}^{\prime}=\left(\left[\tilde{\mathrm{a}}_{k}^{\prime l}, \tilde{\mathrm{a}}_{k}^{\prime u}\right],\left[\dot{\zeta}_{k}^{\prime l}, \dot{⿳}_{k}^{\prime \prime}\right],\left[\dot{\mathrm{b}}_{k}^{\prime l}, \dot{\mathrm{b}}_{k}^{\prime \prime}\right]\right)$ and $\tilde{\mathrm{a}}_{k}=\left(\left[\tilde{\mathrm{a}}_{k}^{l}, \tilde{\mathrm{a}}_{k}^{u}\right],\left[\hat{c}_{k}^{l}, \dot{\zeta}_{k}^{u}\right]\right.$, $\left.\left[\dot{\mathrm{b}}_{k}^{l}, \dot{\mathrm{b}}_{k}^{u}\right]\right)$, such that $\tilde{\mathrm{a}}_{k}^{\prime} \leq \tilde{\mathrm{a}}_{k}$. Then, with $s, t \geq 0, \mathfrak{q} \in \mathbb{Z}^{+}$, we have

$$
\operatorname{IVTSFBMs} s^{s, t}\left(\tilde{\mathrm{a}}_{1}^{\prime}, \tilde{\mathrm{a}}_{2}^{\prime}, \ldots, \tilde{\mathrm{a}}_{\mathrm{m}}^{\prime}\right) \leq \operatorname{IVTSFBMs} s^{s, t}\left(\tilde{\mathrm{a}}_{1}, \tilde{\mathrm{a}}_{2}, \ldots, \tilde{\mathrm{a}}_{\mathrm{m}}\right)
$$

Proof. Let IVTSFBMs $s^{s, t}\left(a_{1}^{\prime}, a_{2}^{\prime}, \ldots, a_{\mathrm{m}}^{\prime}\right)=\left(\left[u_{a}^{\prime l}(x), u_{a}^{\prime u}(x)\right],\left[\bar{\imath}_{a}^{\prime l}(x), \mathbf{i}_{a}^{\prime \prime l}(x)\right],\left[v_{a}^{\prime l}(x), v_{a}^{\prime u}(x)\right]\right)$ and IVTSFBMs $s^{s, t}\left(a_{1}, a_{2}, \ldots, a_{\mathrm{m}}\right)=\left[u_{a}^{l}(x), u_{a}^{u}(x)\right],\left[i_{a}^{l}(x), i_{a}^{u}(x)\right],\left[v_{a}^{l}(x), v_{a}^{u}(x)\right]$. Then, by using the DM, we can prove that $\left[u_{a}^{\prime l}(x), u_{a}^{\prime \prime}(x)\right] \leq\left[u_{a}^{l}(x), u_{a}^{u}(x)\right]$. Since $\left[a_{\overline{\mathrm{l}}}^{\prime l}(x), a_{\overline{\mathrm{l}}}^{\prime \prime}(x)\right] \leq$

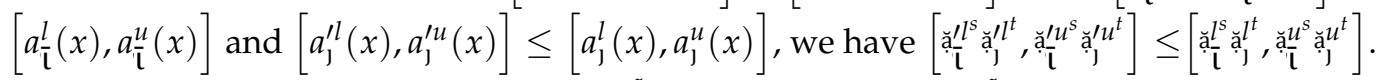

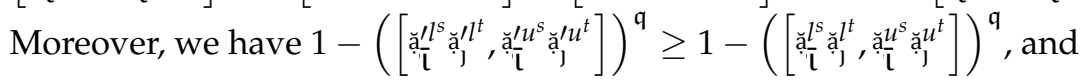

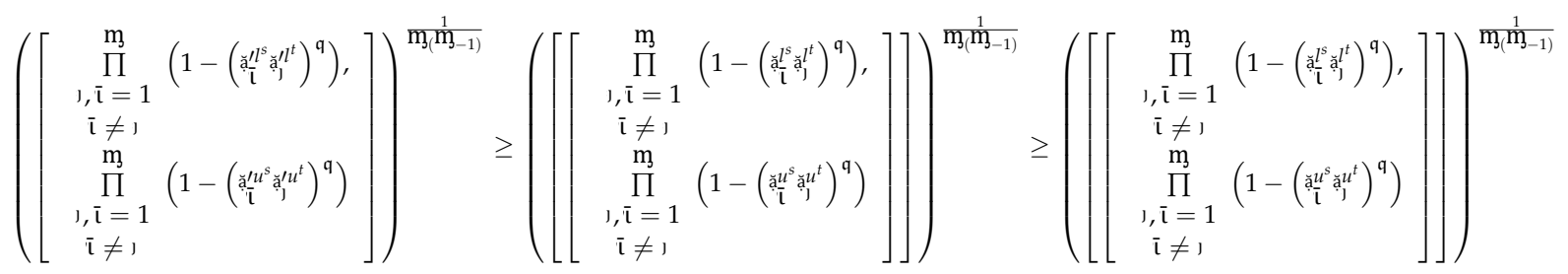

Thus, we have 


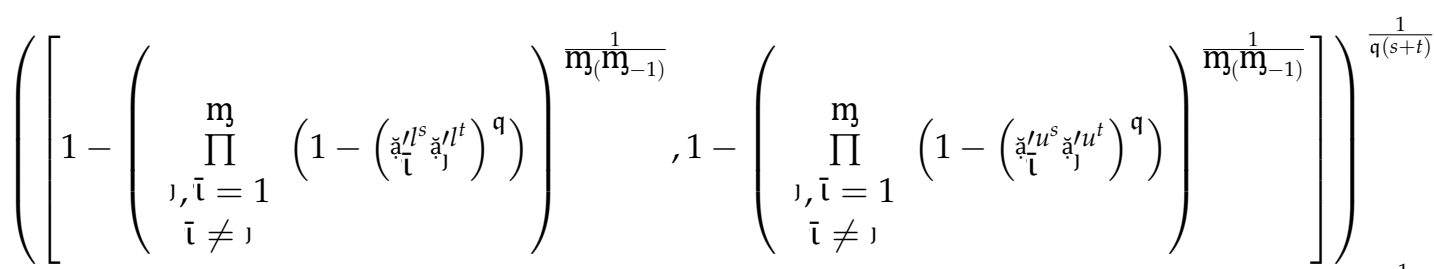

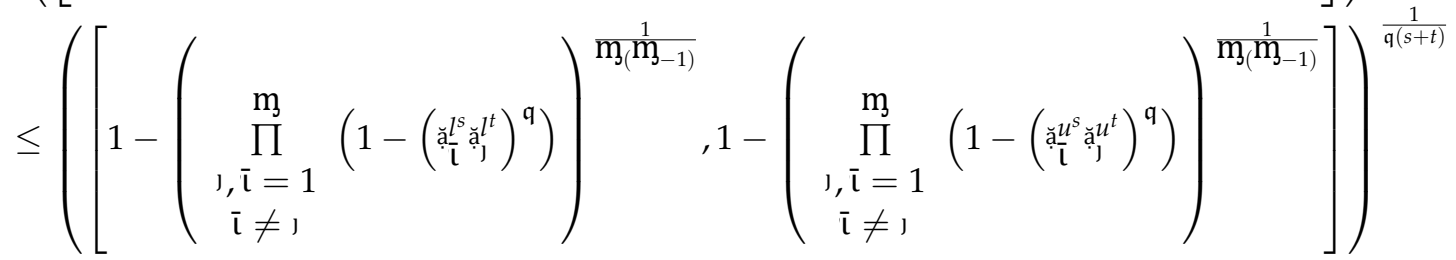

That is, $\left[u_{A}^{\prime l}(x), u_{A}^{\prime \prime}(x)\right] \leq\left[u_{A}^{l}(x), u_{A}^{u}(x)\right]$. Similarly, we can show for the duplet, such that $\left[v_{A}^{\prime l}(x), v_{A}^{\prime u}(x)\right] \geq\left[v_{A}^{l}(x), v_{A}^{u}(x)\right]$ and $\left[\bar{\imath}_{A}^{\prime \prime}(x), \bar{\imath}_{A}^{\prime \prime}(x)\right] \geq\left[\bar{\imath}_{A}^{l}(x), \bar{\imath}_{A}^{u}(x)\right]$.

From the above analysis, we derive $\left(\left[u_{A}^{\prime l}(x), u_{A}^{\prime \prime}(x)\right],\left[{ }^{\prime \prime l}(x), i_{A}^{\prime \prime}(x)\right],\left[v_{A}^{\prime l}(x), v_{A}^{\prime u}(x)\right]\right) \leq$ $\left(\left[u_{A}^{l}(x), u_{A}^{u}(x)\right],\left[\bar{\imath}_{A}^{l}(x), \bar{i}_{A}^{u}(x)\right],\left[v_{A}^{l}(x), v_{A}^{u}(x)\right]\right)$.

$$
\operatorname{IVTSFBMs} s^{s, t}\left(\tilde{\mathrm{a}}_{1}^{\prime}, \tilde{\mathrm{a}}_{2}^{\prime}, \ldots, \tilde{\mathrm{a}}_{\mathrm{m}}^{\prime}\right) \leq \operatorname{IVTSFBMs} s^{s, t}\left(\tilde{\mathrm{a}}_{1}, \tilde{\mathrm{a}}_{2}, \ldots, \tilde{\mathrm{a}}_{\mathrm{m}}\right)
$$

Theorem 4. For any set $X$, let $\tilde{\mathrm{a}}_{k}=\left(\left[\tilde{\mathrm{a}}_{k}^{l}(x), \tilde{\mathrm{a}}_{k}^{u}(x)\right],\left[\hat{c}_{k}^{l}(x), \hat{\zeta}_{k}^{u}(x)\right],\left[\dot{\mathrm{b}}_{k}^{l}(x), \dot{\mathrm{b}}_{k}^{u}(x)\right]\right),(k=1,2$ $\left.\ldots, \mathrm{m}_{3}\right)$ be a collection of IVTSFNs and both $\tilde{\mathrm{a}}^{+}$and $\tilde{\mathrm{a}}^{-}$denote the greatest and smallest IVTSFNs of $\tilde{a}_{k}$ according to Definition 2. Then,

$$
\tilde{\mathrm{a}}^{-} \leq \operatorname{IVTSFBM} M^{s, t}\left(\tilde{\mathrm{a}}_{1}^{\prime}, \tilde{\mathrm{a}}_{2}^{\prime}, \ldots, \tilde{\mathrm{a}}_{\mathrm{m}}^{\prime}\right) \leq \tilde{\mathrm{a}}^{+}
$$

Proof. Based on Equation (13), we derive $\operatorname{IVTSFBM}^{s, t}\left(a^{-}, a^{-}, \ldots, a^{-}\right) \leq \operatorname{IVTSFBM}^{s, t}\left(a_{1}\right.$, $\left.\ldots, a_{\mathrm{m}}\right) \leq \operatorname{IVTSFBM} M^{s, t}\left(a^{+}, \ldots, \ldots, a^{+}\right)$, and by using Theorem 2 , we IVTSFBM $M^{s, t}$ $\left(a^{-}, a^{-}, \ldots, a^{-}\right)=a^{-}, \operatorname{IVTSFBM} M^{s, t}\left(a^{+}, a^{+}, \ldots, a^{+}\right)=a^{+}$. Thus, we obtain $a^{-}$ $\leq \operatorname{IVTSFBM} M^{s, t}\left(a_{1}^{\prime}, a_{2}^{\prime}, \ldots, a_{\mathrm{m}}^{\prime}\right) \leq a^{+}$.

Here, it is important to note that by having the properties of boundedness and monotonicity, the IVTSFBM operator can be used in the study of group consensus systems [57].

By using Equation (10), we will demonstrate some cases, which is discussed below.

1. For $t=0$, we obtain

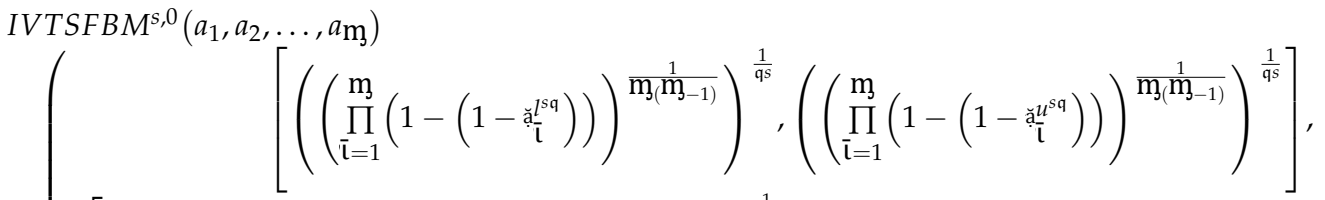

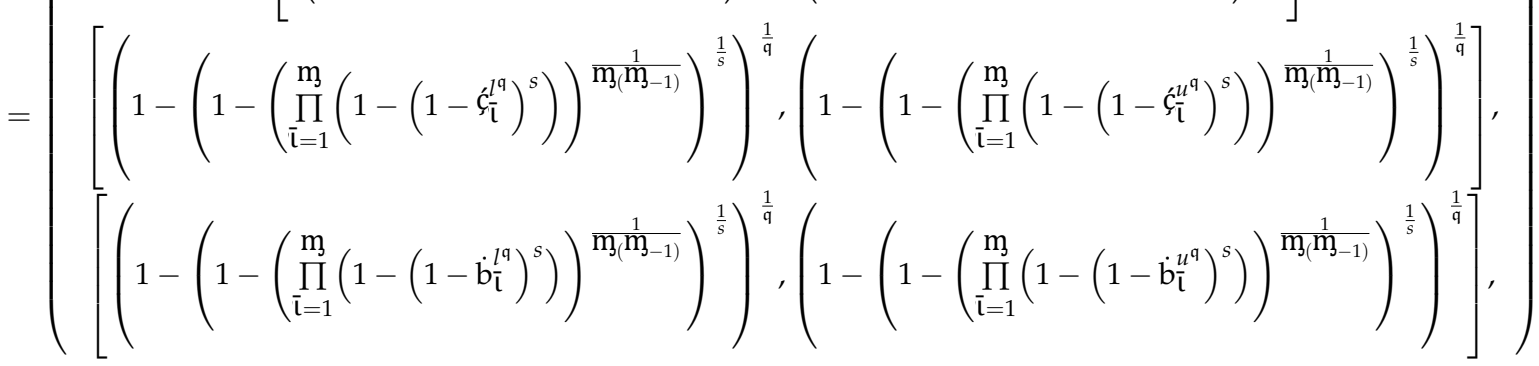


2. For $s=1, t=0$, we obtain

$$
\begin{aligned}
& \operatorname{IVTSFBM} M^{1,0}\left(a_{1}^{\prime}, a_{2}^{\prime}, \ldots, a_{\mathrm{m}}^{\prime}\right)
\end{aligned}
$$

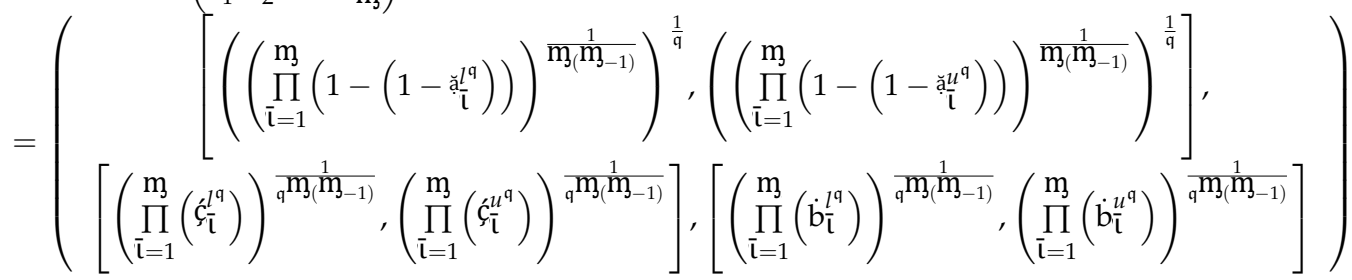

3. For $s=0$, we obtain

$$
\begin{aligned}
& \operatorname{IVTSFBM}^{\mathrm{s}, 0}\left(a_{1}^{\prime}, a_{2}^{\prime}, \ldots, a_{\mathrm{m}}^{\prime}\right)
\end{aligned}
$$

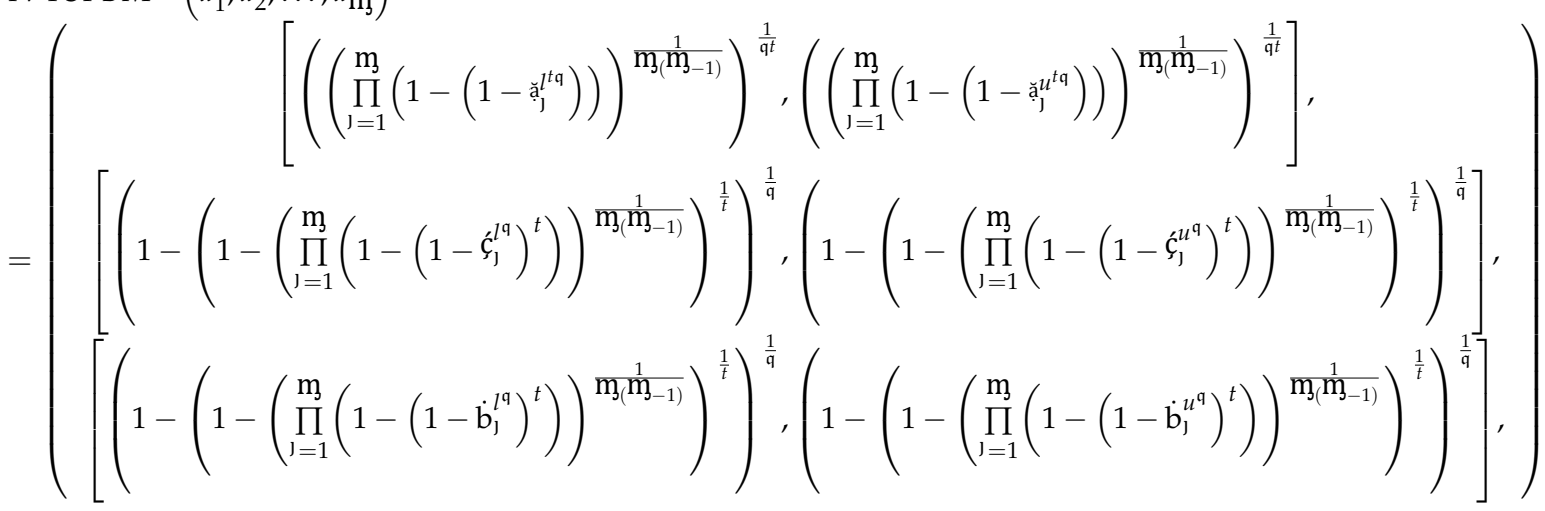

4. For $s=t=1$, we obtain

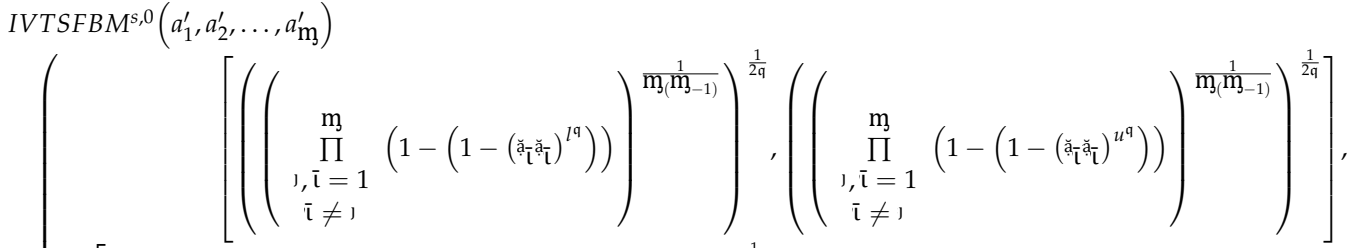

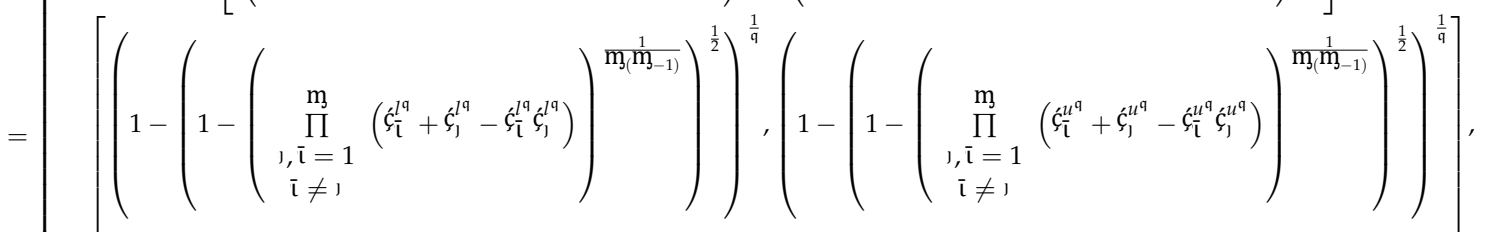

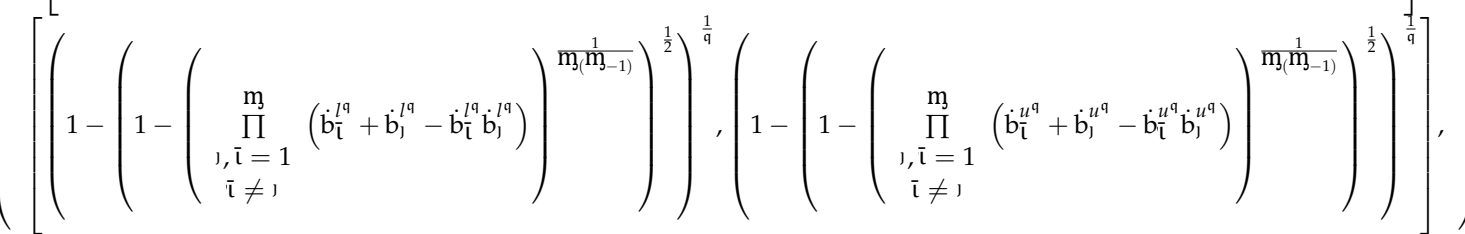

5. For $q=1$, we obtain the Intuitionistic fuzzy BMO. 


$$
\begin{aligned}
& \operatorname{IVTSFBM} M^{s, t}\left(a_{1}^{\prime}, a_{2}^{\prime}, \ldots, a_{\mathrm{m}}^{\prime}\right)
\end{aligned}
$$

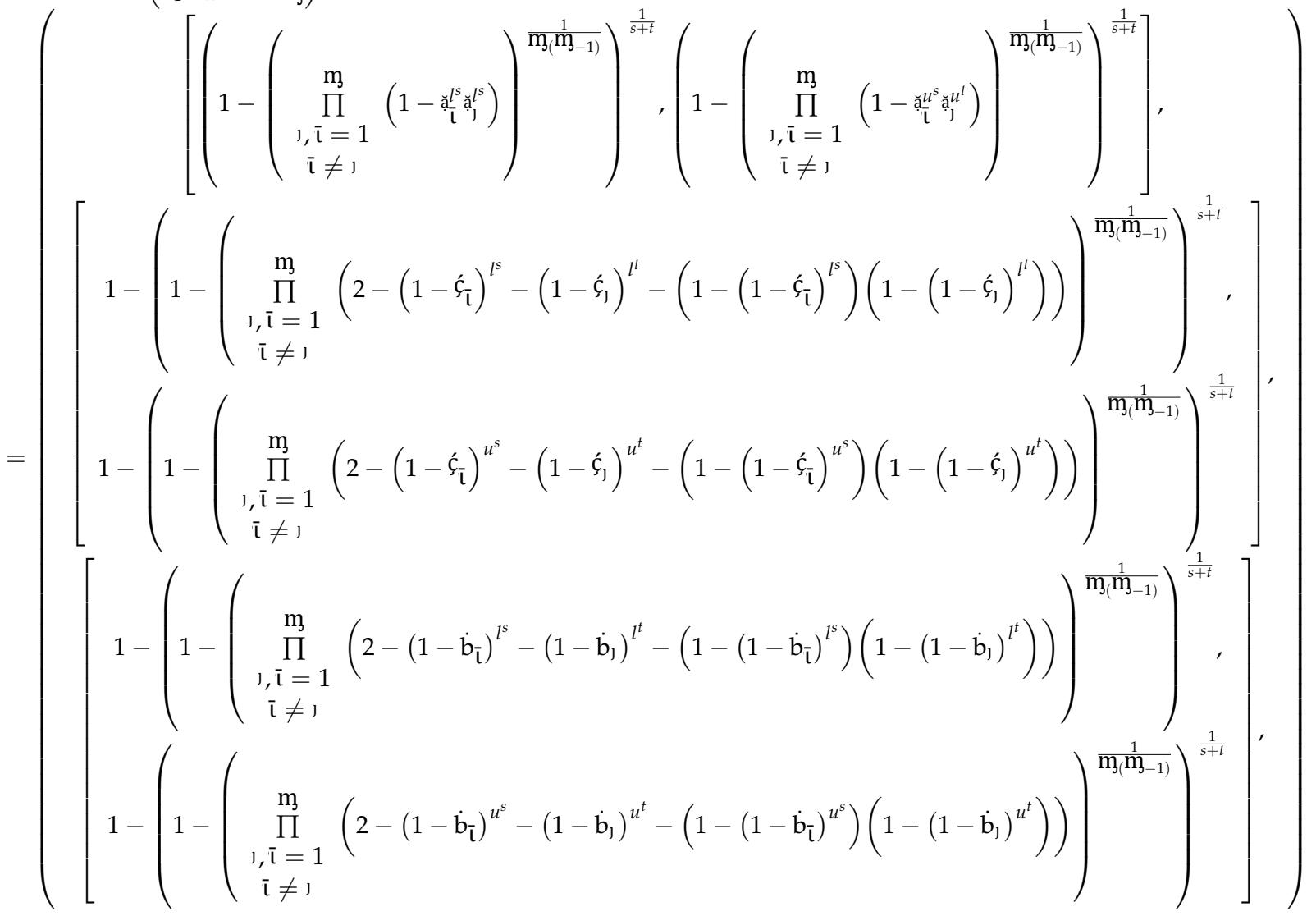

6. For $\mathfrak{q}=2$, we obtain the Pythagorean fuzzy BMO. 


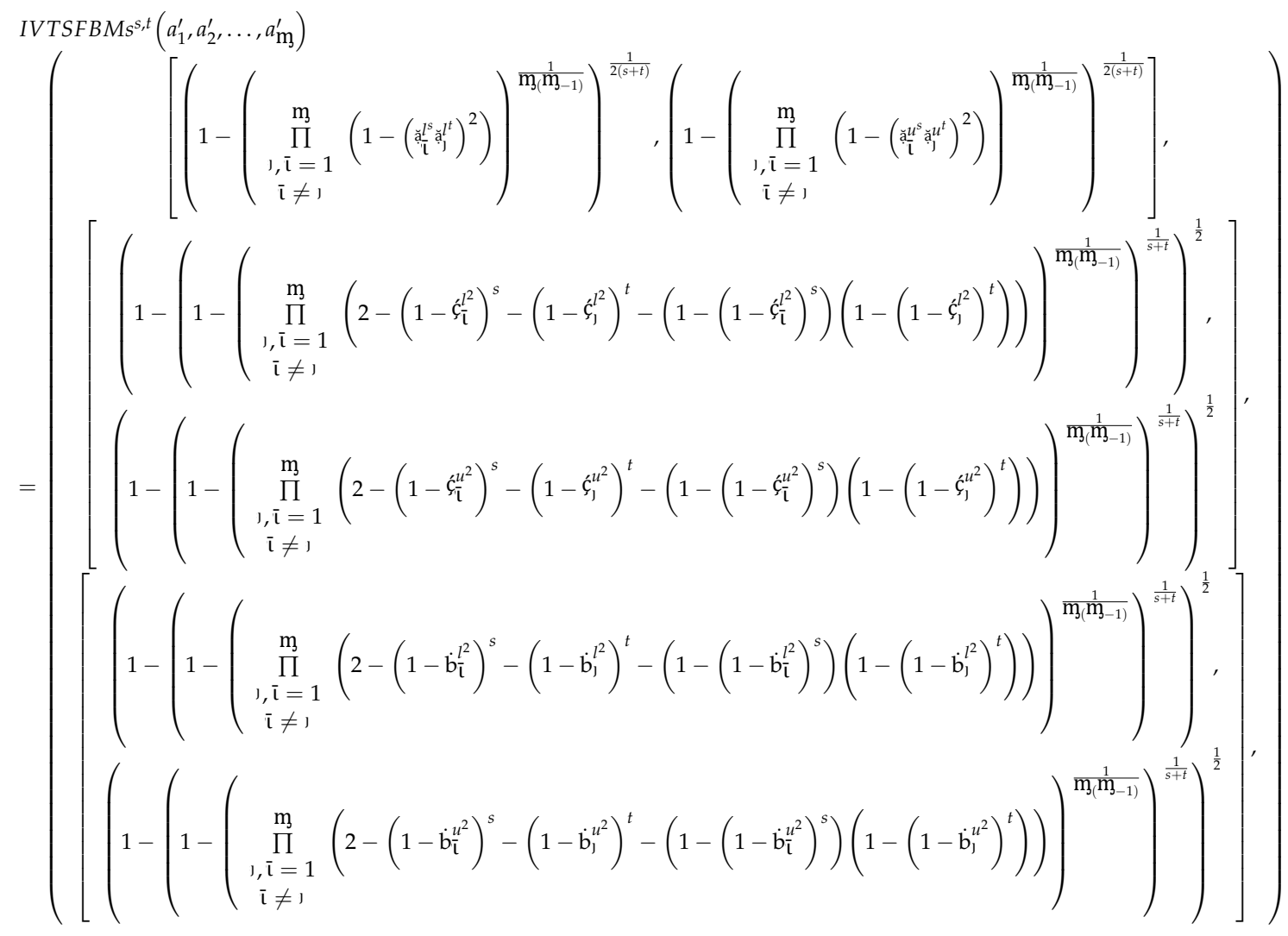

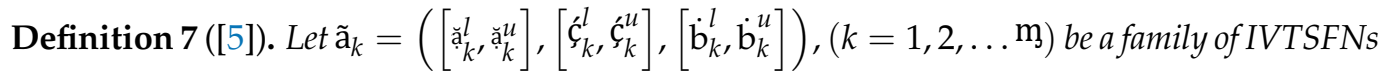
with $s, t \geq 0, \mathfrak{q} \in \mathbb{Z}^{+}$and IVTSFWBM $: \Omega^{\mathrm{m}} \rightarrow \Omega$, if

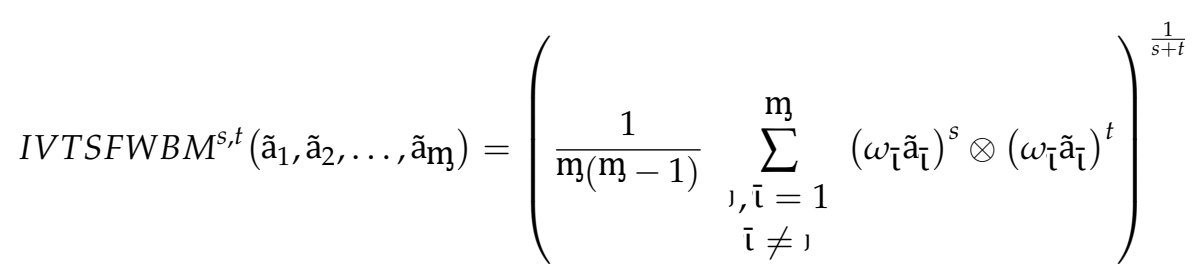

Here, the weight vector is denoted by $\omega_{\bar{\imath}}$ with a rule, that is, the sum of all $\omega_{\bar{\imath}}$ is equal to 1 . From Definition 7, we obtain the following result.

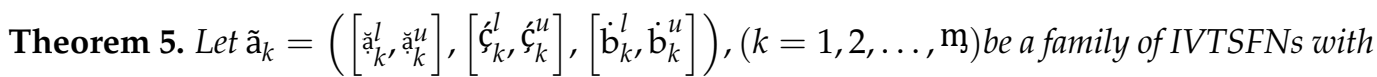
$s, t \geq 0, \mathfrak{q} \in \mathbb{Z}^{+}$. By using Equation (21) and Definition 2, we obtain 


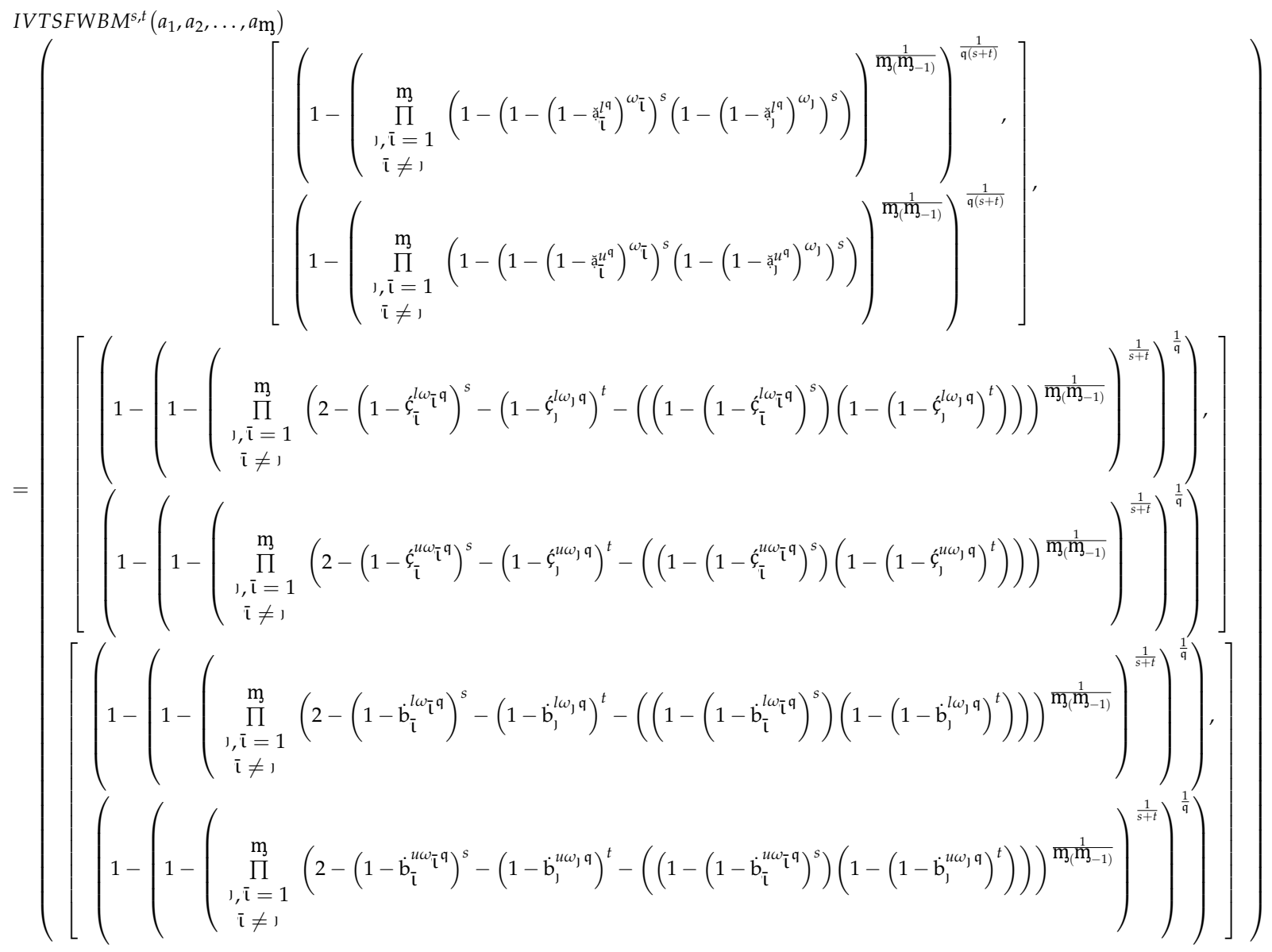

Proof . The proof is similar to Theorem 1 and omitted here.

Remark 1. The above stated theorem is likely to satisfy the properties discussed in Theorems 2-4.

Now, we discuss the geometric BM operators for IVTSFNs, which can also be regarded as duals of BM operators.

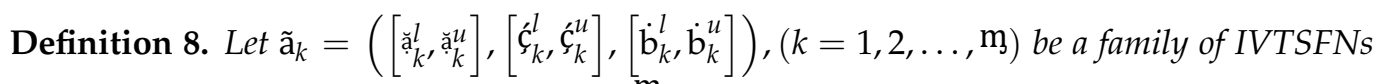
with $s, t \geq 0, \mathfrak{q} \in \mathbb{Z}^{+}$and IVTSFGBM $: \Omega^{\mathrm{m}} \rightarrow \Omega$, if

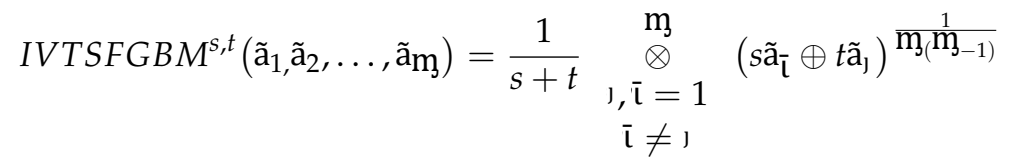

From Definition 8 and operational laws of Definition 2, we derive the following result.

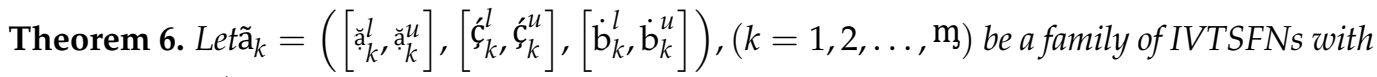
$s, t \geq 0, \mathfrak{q} \in \mathbb{Z}^{+}$. By using Equation (22) and Definition 2, we obtain: 


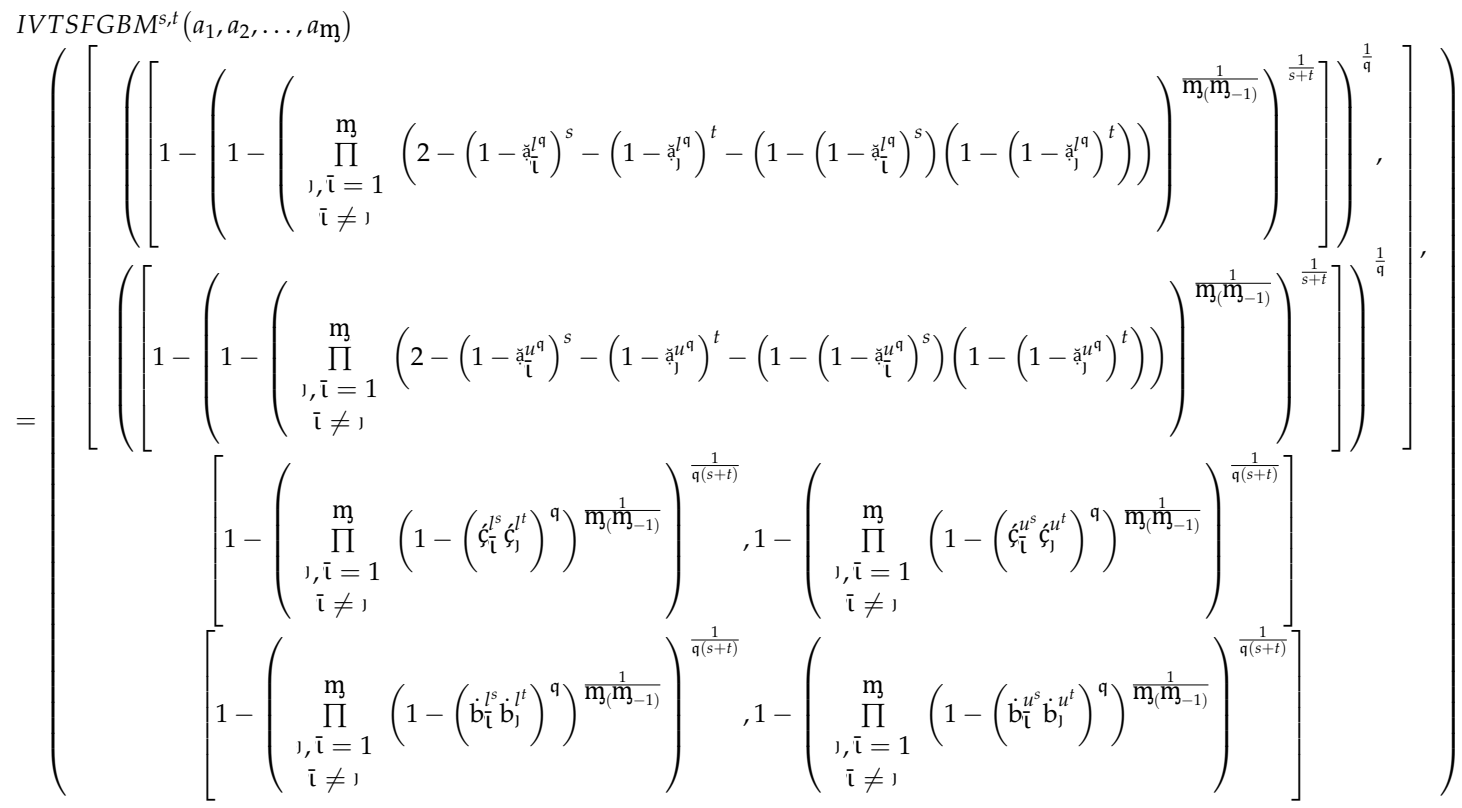

Proof. Straightforward.

Furthermore, idempotency, monotonicity, and boundedness are desirable properties of the IVTSFBM as discussed in Corollaries 1-3.

Corollary 1. For any set $X$, let $\left\{\tilde{a}_{1}, \tilde{a}_{2}, \ldots, \tilde{a}_{m}\right\}$ be a collection of IVTSFNs. If all $\tilde{a}_{k},(k=1,2$, $\left.\ldots, \mathrm{m}_{3}\right)$ are equal, that is, $\tilde{\mathrm{a}}_{k}=\tilde{\mathrm{a}}=\left[\tilde{\mathrm{a}}^{l}, \tilde{\mathrm{a}}^{u}\right],\left[\hat{c}^{l}, \hat{c}^{u}\right],\left[\dot{\mathrm{b}}^{l}, \dot{\mathrm{b}}^{u}\right]$ with $s, t \geq 0, \mathfrak{q} \in \mathbb{Z}^{+}$, then

$$
\operatorname{IVTSFGBM} M^{s, t}\left(\tilde{\mathrm{a}}_{1}, \tilde{\mathrm{a}}_{2}, \ldots, \tilde{\mathrm{a}}_{\mathrm{m}}\right)=\tilde{\mathrm{a}}
$$

Proof. Straightforward.

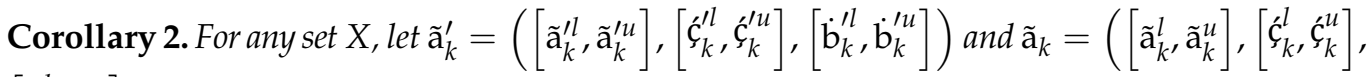
$\left.\left[\dot{\mathrm{b}}_{k}^{l}, \dot{\mathrm{b}}_{k}^{u}\right]\right)$, such that $\tilde{\mathrm{a}}_{k}^{\prime} \leq \tilde{\mathrm{a}}_{k}$. Then, with $s, t \geq 0, \mathfrak{q} \in \mathbb{Z}^{+}$, we have

$$
\operatorname{IVTSFGBMs} s^{s, t}\left(\tilde{\mathrm{a}}_{1}^{\prime}, \tilde{\mathrm{a}}_{2}^{\prime}, \ldots, \tilde{\mathrm{a}}_{\mathrm{m}}^{\prime}\right) \leq \operatorname{IVTSFGBMs} s^{s, t}\left(\tilde{\mathrm{a}}_{1}, \tilde{a}_{2}, \ldots, \tilde{\mathrm{a}}_{\mathrm{m}}\right)
$$

Proof. Straightforward.

Corollary 3. For any set $X$, let $\tilde{\mathrm{a}}_{k}=\left(\left[\tilde{\mathrm{a}}_{k}^{l}(x), \tilde{\mathrm{a}}_{k}^{u}(x)\right],\left[\hat{c}_{k}^{l}(x), \dot{\varphi}_{k}^{u}(x)\right],\left[\dot{\mathrm{b}}_{k}^{l}(x), \dot{\mathrm{b}}_{k}^{u}(x)\right]\right)$, $(k=1,2 \ldots, \mathrm{m})$ be a collection of IVTSFNs and both $\tilde{\mathrm{a}}^{+}$and $\tilde{\mathrm{a}}^{-}$denote the greatest and smallest IVTSFNs of $\tilde{a}_{k}$ according to Definition 2. Then,

$$
\tilde{\mathrm{a}}^{-} \leq \operatorname{IVTSFBM} M^{s, t}\left(\tilde{\mathrm{a}}_{1}^{\prime}, \tilde{\mathrm{a}}_{2}^{\prime}, \ldots, \tilde{\mathrm{a}}_{\mathrm{m}}^{\prime}\right) \leq \tilde{\mathrm{a}}^{+}
$$

Proof. Straightforward.

To incorporate the weights of experts, the notion of weighted BM operators is discussed as follows: 


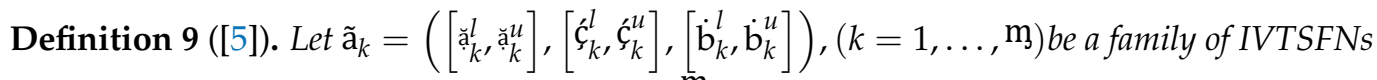
with $s, t \geq 0, \mathfrak{q} \geq 1$. Then, IVTSFWGBM $: \Omega^{\mathrm{m}} \rightarrow \Omega$ is a map defined as:

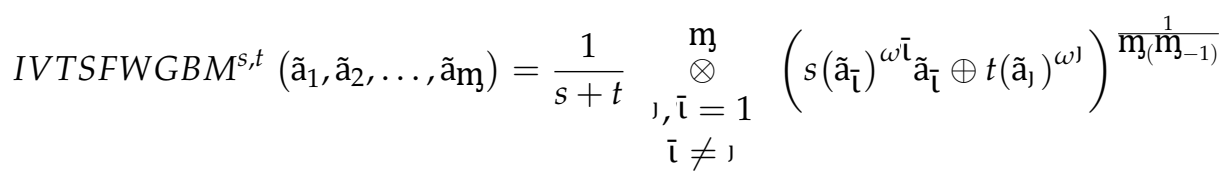

where $\omega_{\bar{\imath}}$ is a weight vector with a rule, that is, the sum of all $\omega_{\bar{\imath}}$ is equal to 1 . By using Definition 9, we obtain the following result.

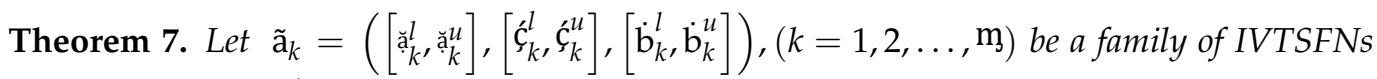
with $s, t \geq 0, \mathfrak{q} \in \mathbb{Z}^{+}$. By using Equation (27), we obtain:

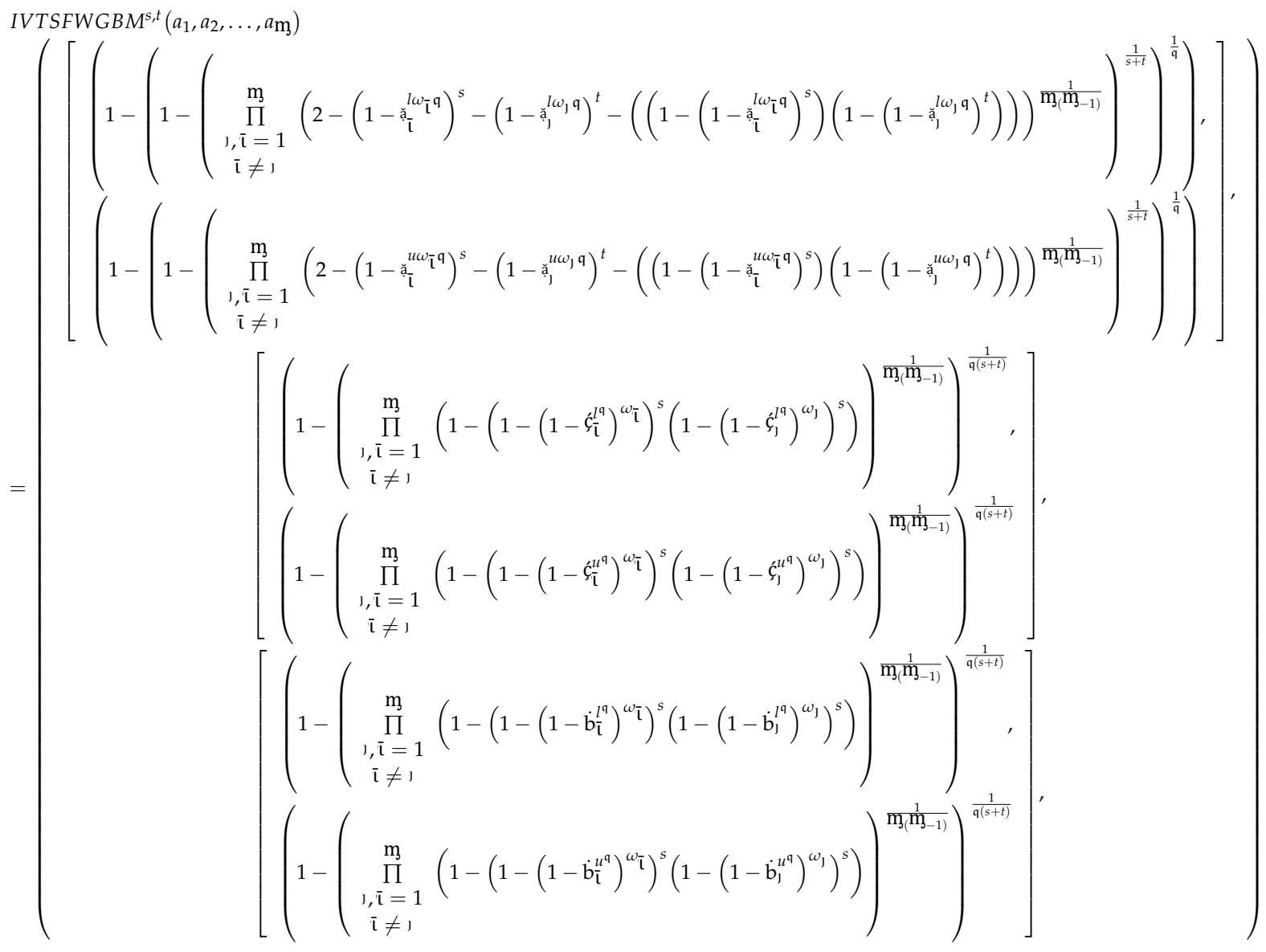

Proof. Straightforward.

Furthermore, idempotency, monotonicity, and boundedness are desirable properties of the IVTSFWGBM as discussed in Corollaries 1-3.

\section{MAGDM Methods by Using Investigated Operators Based on IVTSFSs}

In this paper, we develop a procedure of the MAGDM technique through the IVTSFBMO operator, IVTSFWBM operator, IVTSFGBM operator, and IVTSFDWGBM operator to discover the consistency and ability of the analyzed operators. Thus, select the family

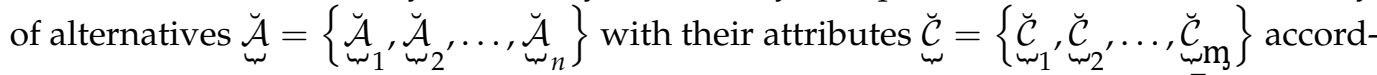
ing to their weight vectors with expressions such that $\omega=\left(\omega_{1}, \omega_{2}, \ldots, \omega_{n}\right)^{T}$, where $\omega_{\overline{\mathbf{\imath}}}$ 
is a weight vector with a rule, that is, the sum of all $\omega_{\bar{\imath}}$ is equal to 1 . To cope with the above problems, take the decision matrix $Q=\left(\tilde{a}_{\overline{\mathbf{l}} \mathbf{\jmath}}\right)_{n \times} \mathrm{m}$, whose every term is in the form

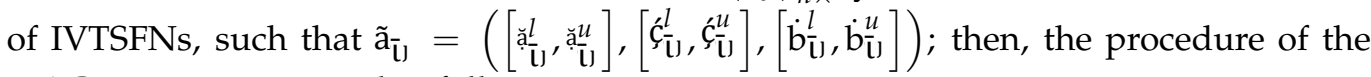
MAGDM is summarized as follow:

Step 1: Develop the decision matrices.

Step 2: Normalize the decision matrix, whose every term is in the form of IVTSFNs.

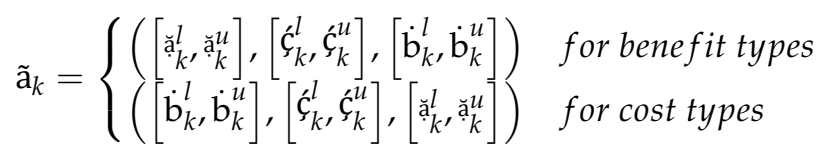

Step 3: By using the idea of the IVTSFWBM operator, aggregate the normalized decision matrices.

Step 4: Revise Step 2 again by using the idea of IVTSFWGBM operators to aggregate the decision matrices.

Step 5: Using the concept score functions, examine the score values of the aggregated values of Step 3.

Step 6: By using the score values, we rank the alternatives and examine the best one.

Step 7: The end.

Example 1. Solar panels are renewable, $\mathrm{CO}_{2}$ free, and have a low operating cost. Solar panels play an important role in the production of electricity by transforming energy from the sun to electricity. The process in which electricity is produced from the sun does not require any cost. There are many kinds of solar cells but certain kinds are discussed in our research paper. Some solar cells are organic semiconductors, such as organic solar cells, which are sometimes denoted as plastic solar cells or polymer solar cells, which are made of carbon-based material. Conversely, some solar cells are inorganic semiconductors, such as silicon solar cells, Perovskite solar cells, Hetro-junction solar cells, and triple-junction amorphous silicon alloy solar cells. Ismail Industries Limited is the largest company which is located in Faisalabad, Pakistan. Manufacturing biscuits, snacks, etc., are under the brand of candy and bissconi. Considering the limited electricity and that the industry is not able to satisfy the required task, the industry needs to produce electricity through solar energy; in such a case, the company must choose the best solar cell, which increases the generation of efficiency, lessens the cost, and is more reliable. The industry has a team of three experts who characterized the following set of alternatives to be analyzed:

$\breve{\mathcal{A}}:$ organic solar cell;

$\breve{\mathcal{A}}_{2}$ : silicon solar cell;

$\breve{\mathcal{A}}_{3}$ : Perovskite solar cell;

$\breve{\mathcal{A}}_{4}$ : triple-junction amorphous silicon alloy solar cell; and

$\breve{\mathcal{A}}_{5}$ : hetro-junction solar cell.

To judge these, the association thinks regarding the practical issue as the basis for the following year. Based on these, they need to judge procedure under the associated four commonassets:

$\breve{\mathcal{C}}_{\mathrm{C}_{1}}$ :cost of the solar cell per square meter;

$\underset{\mathcal{C}}{\breve{C}}$ : power conversion efficiency;

$\stackrel{\sim}{\breve{C}}_{2}^{\breve{c}}$ :led-free (environmentally free); and

$\underset{\mathrm{C}}{\breve{C}}:$ :life span of an individual solar cell.

The phases of the examined algorithm are deliberated in the following ways by using the values of weight vectors, such that $(0.3,0.2,0.1,0.25,0.15)$. Then, execute the following steps.

Step 1: We develop the decision matrices whose details are in the form of Tables 1-3. 
Table 1. T-spherical fuzzy decision matrix $A^{1}$ given by $D_{1}$.

\begin{tabular}{|c|c|c|c|c|}
\hline Alternative/Attributes & $\underbrace{\breve{c}}_{1}$ & $\underbrace{\breve{\mathcal{C}}}_{2}$ & $\underbrace{\breve{\mathcal{C}}}_{3}$ & $\underbrace{\breve{\mathcal{C}}}_{4}$ \\
\hline$\stackrel{\breve{A}}{1}_{1}$ & $\left.\begin{array}{l}{[0.23,0.41],} \\
{[0.34,0.55],} \\
{[0.39,0.51]}\end{array}\right)$ & $\left.\begin{array}{l}{[0.25,0.35],} \\
{[0.48,0.69],} \\
{[0.34,0.46]}\end{array}\right)$ & $\left.\begin{array}{l}{[0.19,0.28],} \\
{[0.34,0.63],} \\
{[0.67,0.78]}\end{array}\right)$ & $\left.\begin{array}{l}{[0.34,0.45],} \\
{[0.57,0.65],} \\
{[0.11,0.34]}\end{array}\right)$ \\
\hline 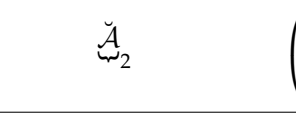 & $\begin{array}{l}{[0.23,0.35],} \\
{[0.32,0.47],} \\
{[0.42,0.54]}\end{array}$ & $\left.\begin{array}{l}{[0.27,0.41],} \\
{[0.44,0.59],} \\
{[0.38,0.49]}\end{array}\right)$ & $\left.\begin{array}{l}{[0.32,0.54],} \\
{[0.49,0.64],} \\
{[0.66,0.79]}\end{array}\right)$ & {$\left[\begin{array}{l}0.39,0.62], \\
{[0.55,0.72],} \\
{[0.17,0.32]}\end{array}\right)$} \\
\hline 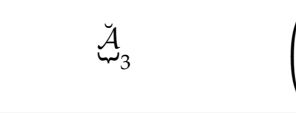 & $\begin{array}{l}{[0.25,0.33],} \\
{[0.31,0.44],} \\
{[0.44,0.52]}\end{array}$ & $\left.\begin{array}{l}{[0.32,0.44],} \\
{[0.42,0.56],} \\
{[0.46,0.56]}\end{array}\right)$ & $\left.\begin{array}{l}{[0.38,0.47],} \\
{[0.51,0.62],} \\
{[0.55,0.69]}\end{array}\right)$ & {$\left[\begin{array}{l}0.41,0.58], \\
{[0.62,0.75],} \\
{[0.15,0.37]}\end{array}\right)$} \\
\hline$\stackrel{\breve{w}}{4}_{4}$ & $\left.\begin{array}{l}{[0.21,0.43],} \\
{[0.33,0.44],} \\
{[0.48,0.49]}\end{array}\right)$ & $\left.\begin{array}{l}{[0.35,0.53],} \\
{[0.44,0.53],} \\
{[0.43,0.53]}\end{array}\right)$ & $\begin{array}{l}{[0.41,0.49],} \\
{[0.53,0.61]} \\
{[0.53,0.65]}\end{array}$ & $\left.\begin{array}{l}{[0.44,0.56],} \\
{[0.65,0.72],} \\
{[0.18,0.33]}\end{array}\right)$ \\
\hline 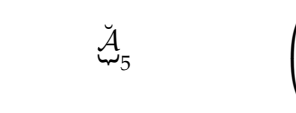 & $\left.\begin{array}{l}{[0.25,0.35],} \\
{[0.37,0.46],} \\
{[0.46,0.59]}\end{array}\right)$ & $\left.\begin{array}{l}{[0.33,0.47],} \\
{[0.49,0.55],} \\
{[0.44,0.54]}\end{array}\right)$ & $\left.\begin{array}{l}0.46,0.59], \\
{[0.55,0.63],} \\
{[0.55,0.67]}\end{array}\right)$ & $\left.\begin{array}{l}{[0.48,0.55],} \\
{[0.62,0.75]} \\
{[0.15,0.23]}\end{array}\right)$ \\
\hline
\end{tabular}

Table 2. T-spherical fuzzy decision matrix $A^{2}$ given by $D_{2}$.

\begin{tabular}{|c|c|c|c|c|}
\hline Alternative/Attributes & $\stackrel{\breve{w}}{1}^{\breve{\mathcal{C}}}$ & $\underbrace{\breve{c}}_{w_{2}}$ & $\underbrace{\breve{c}}_{w_{3}}$ & $\underbrace{\breve{\mathcal{C}}}_{\omega_{4}}$ \\
\hline 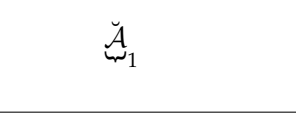 & {$\left[\begin{array}{l}{[0.32,0.45],} \\
{[0.29,0.57],} \\
{[0.47,0.69]}\end{array}\right)$} & $\left.\begin{array}{l}{[0.24,0.34],} \\
{[0.45,0.65],} \\
{[0.39,0.51]}\end{array}\right)$ & $\left.\begin{array}{l}{[0.21,0.31],} \\
{[0.32,0.59],} \\
{[0.62,0.81]}\end{array}\right)$ & $\begin{array}{l}{[0.29,0.41],} \\
{[0.55,0.68],} \\
{[0.14,0.25]}\end{array}$ \\
\hline$\stackrel{\breve{A}}{2}_{2}$ & $\begin{array}{l}{[0.33,0.47],} \\
{[0.28,0.39]} \\
{[0.44,0.66]}\end{array}$ & $\begin{array}{l}{[0.29,0.38],} \\
{[0.43,0.65],} \\
{[0.35,0.55]}\end{array}$ & $\left.\begin{array}{c}{[0.17,0.33]} \\
{[0.37,0.55]} \\
0.66,0.83]\end{array}\right)$ & $\begin{array}{l}{[0.43,0.59],} \\
{[0.62,0.72],} \\
{[0.18,0.35]}\end{array}$ \\
\hline$\stackrel{\breve{A}}{3}_{3}$ & $\left.\begin{array}{l}{[0.44,0.54],} \\
{[0.26,0.41],} \\
0.42,0.64]\end{array}\right)$ & $\begin{array}{l}{[0.35,0.47],} \\
{[0.34,0.66],} \\
{[0.33,0.59]}\end{array}$ & $\begin{array}{l}{[0.27,0.39]} \\
{[0.39,0.49]} \\
{[0.64,0.78]}\end{array}$ & $\begin{array}{l}{[0.13,0.62],} \\
{[0.52,0.66],} \\
{[0.22,0.31]}\end{array}$ \\
\hline$\stackrel{\breve{\mathcal{A}}}{4}_{4}$ & $\left.\begin{array}{l}{[0.42,0.52],} \\
{[0.36,0.41],} \\
{[0.44,0.66]}\end{array}\right)$ & $\left.\begin{array}{l}{[0.33,0.44],} \\
{[0.39,0.62],} \\
{[0.39,0.54]}\end{array}\right)$ & $\begin{array}{l}{[0.22,0.35]} \\
{[0.41,0.67]} \\
{[0.66,0.72]}\end{array}$ & $\begin{array}{l}{[0.15,0.55],} \\
{[0.55,0.62],} \\
{[0.24,0.33]}\end{array}$ \\
\hline$\breve{w}_{5}$ & {$\left[\begin{array}{l}0.44,0.55], \\
{[0.32,0.43],} \\
{[0.48,0.62]}\end{array}\right)$} & $\left.\begin{array}{l}{[0.35,0.46],} \\
{[0.37,0.65],} \\
{[0.43,0.59]}\end{array}\right)$ & $\left.\begin{array}{l}{[0.27,0.39],} \\
{[0.44,0.45],} \\
{[0.62,0.75]}\end{array}\right)$ & $\begin{array}{l}{[0.19,0.45],} \\
{[0.58,0.66],} \\
{[0.78,0.36]}\end{array}$ \\
\hline
\end{tabular}

Table 3. T-spherical fuzzy decision matrix $A^{3}$ given by $D_{3}$.

\begin{tabular}{|c|c|c|c|c|}
\hline Alternative/Attributes & $\underbrace{\breve{\mathcal{C}}}_{1}$ & $\underbrace{\breve{\mathcal{C}}}_{2}$ & $\underbrace{\breve{\mathcal{C}}}_{3}$ & $\stackrel{\breve{\mathcal{C}}}{4}_{4}$ \\
\hline$\stackrel{\breve{A}}{\mathcal{A}}_{1}$ & $\begin{array}{l}{[0.18,0.38]} \\
{[0.37,0.55]} \\
{[0.44,0.63]}\end{array}$ & $\begin{array}{l}{[0.27,0.45]} \\
{[0.52,0.67]} \\
{[0.32,0.48]}\end{array}$ & $\begin{array}{l}{[0.31,0.52]} \\
{[0.37,0.49]} \\
{[0.56,0.72]}\end{array}$ & $\begin{array}{l}{[0.39,0.62]} \\
{[0.41,0.58]} \\
{[0.24,0.43]}\end{array}$ \\
\hline$\underbrace{\breve{A}_{2}}$ & $\begin{array}{l}{[0.22,0.36]} \\
{[0.33,0.53]} \\
{[0.44,0.61]}\end{array}$ & $\begin{array}{l}{[0.29,0.44]} \\
{[0.55,0.65]} \\
{[0.35,0.43]}\end{array}$ & $\begin{array}{l}{[0.33,0.56]} \\
{[0.39,0.48]} \\
{[0.54,0.67]}\end{array}$ & $\begin{array}{l}{[0.41,0.61]} \\
{[0.44,0.55]} \\
{[0.29,0.38]}\end{array}$ \\
\hline$\underbrace{\breve{\mathcal{A}}}$ & $\begin{array}{l}{[0.16,0.32],} \\
{[0.350 .55],} \\
{[0.42,0.63]}\end{array}$ & $\begin{array}{l}{[0.25,0.47]} \\
{[0.57,0.61]} \\
{[0.36,0.43]}\end{array}$ & $\begin{array}{c}{[0.31,0.55]} \\
{[0.33,0.45]} \\
{[0.53,0.68]}\end{array}$ & $\begin{array}{l}{[0.44,0.65]} \\
{[0.46,0.53]} \\
{[0.25,0.36]}\end{array}$ \\
\hline 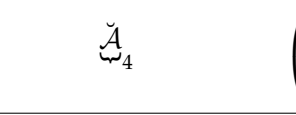 & $\begin{array}{l}{[0.18,0.34],} \\
{[0.33,0.45],} \\
{[0.44,0.66]}\end{array}$ & $\begin{array}{l}{[0.28,0.44]} \\
{[0.51,0.65]} \\
{[0.32,0.55]}\end{array}$ & $\begin{array}{c}{[0.34,, 0.52],} \\
{[0.32,0.52],} \\
{[0.58,0.71]}\end{array}$ & $\begin{array}{l}{[0.46,0.62]} \\
{[0.56,0.68]} \\
{[0.35,0.48]}\end{array}$ \\
\hline$\underbrace{\breve{A}_{5}}_{5}$ & $\begin{array}{l}{[0.19,0.36],} \\
{[0.31,0.44],} \\
{[0.49,0.64]}\end{array}$ & $\begin{array}{l}{[0.26,0.48],} \\
{[0.55,0.62],} \\
{[0.36,0.58]}\end{array}$ & $\begin{array}{l}{[0.36,0.54],} \\
{[0.36,0.55]} \\
{[0.54,0.69]}\end{array}$ & $\begin{array}{l}{[0.48,0.66]} \\
{[0.54,0.64]} \\
{[0.38,0.49]}\end{array}$ \\
\hline
\end{tabular}

Step 2: Normalize the decision matrix whose every term is in the form of IVTSFNs. All the restrained principles are of the identical type, thus they do not require the consistency done. 
Step 3: Using the idea of IVTSFBO to aggregate the normalized decision matrix is discussed in the form of Table 4 .

Table 4. Aggregated matrix by using the information in Tables 1-3.

\begin{tabular}{|c|c|c|c|c|c|c|c|c|c|c|c|c|}
\hline \multirow[b]{3}{*}{$\underbrace{\breve{\mathcal{C}_{1}}}_{w_{1}}$} & \multicolumn{6}{|c|}{$\underbrace{\breve{\mathcal{A}}}_{1}$} & \multicolumn{6}{|c|}{$\breve{\mathcal{A}}_{2}$} \\
\hline & \multicolumn{2}{|c|}{ MD } & \multicolumn{2}{|c|}{$\mathrm{AD}$} & \multicolumn{2}{|c|}{ NMD } & \multicolumn{2}{|c|}{ MD } & \multicolumn{2}{|c|}{$\mathrm{AD}$} & \multicolumn{2}{|c|}{ NMD } \\
\hline & 0.21 & 0.40 & 0.25 & 0.46 & 0.36 & 0.53 & 0.24 & 0.38 & 0.24 & 0.34 & 0.35 & 0.52 \\
\hline $\mathrm{w}_{1}^{\breve{\mathcal{C}}}$ & 0.26 & 0.38 & 0.37 & 0.56 & 0.30 & 0.40 & 0.29 & 0.41 & 0.35 & 0.52 & 0.29 & 0.43 \\
\hline$\breve{w}_{1}^{\breve{\mathcal{C}}}$ & 0.23 & 0.35 & 0.26 & 0.50 & 0.53 & 0.70 & 0.23 & 0.43 & 0.34 & 0.49 & 0.55 & 0.72 \\
\hline \multirow[t]{3}{*}{$\breve{C}_{1}^{\breve{C}}$} & 0.34 & 0.49 & 0.46 & 0.56 & 0.10 & 0.23 & 0.41 & 0.61 & 0.49 & 0.61 & 0.14 & 0.27 \\
\hline & \multicolumn{6}{|c|}{$\breve{\mathcal{A}}_{3}$} & \multicolumn{6}{|c|}{$\breve{\mathcal{A}}_{4}$} \\
\hline & \multicolumn{2}{|c|}{ MD } & \multicolumn{2}{|c|}{$\mathrm{AD}$} & \multicolumn{2}{|c|}{ NMD } & \multicolumn{2}{|c|}{ MD } & \multicolumn{2}{|c|}{$\mathrm{AD}$} & \multicolumn{2}{|c|}{ NMD } \\
\hline$\underbrace{\breve{C}}$ & 0.19 & 0.35 & 0.22 & 0.34 & 0.34 & 0.50 & 0.21 & 0.39 & 0.28 & 0.34 & 0.37 & 0.51 \\
\hline $\mathrm{w}_{1}^{\breve{\mathcal{C}}}$ & 0.28 & 0.46 & 0.30 & 0.52 & 0.32 & 0.48 & 0.30 & 0.45 & 0.33 & 0.49 & 0.33 & 0.44 \\
\hline$\breve{C}_{1}$ & 0.30 & 0.46 & 0.36 & 0.45 & 0.50 & 0.65 & 0.28 & 0.43 & 0.38 & 0.44 & 0.51 & 0.59 \\
\hline \multirow[t]{3}{*}{$\breve{C}_{1}$} & 0.19 & 0.62 & 0.46 & 0.60 & 0.16 & 0.27 & 0.22 & 0.58 & 0.49 & 0.56 & 0.17 & 0.26 \\
\hline & \multicolumn{6}{|c|}{$\stackrel{\breve{A}}{5}_{5}$} & & & & & & \\
\hline & \multicolumn{2}{|c|}{ MD } & \multicolumn{2}{|c|}{$\mathrm{AD}$} & \multicolumn{2}{|c|}{ NMD } & & & & & & \\
\hline $\mathrm{C}_{1}$ & 0.22 & 0.39 & 0.27 & 0.36 & 0.38 & 0.52 & & & & & & \\
\hline$\breve{C}_{1}$ & 0.29 & 0.47 & 0.34 & 0.51 & 0.35 & 0.47 & & & & & & \\
\hline $\mathrm{C}_{1}$ & 0.33 & 0.48 & 0.40 & 0.45 & 0.49 & 0.62 & & & & & & \\
\hline 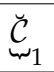 & 0.27 & 0.54 & 0.49 & 0.60 & 0.19 & 0.26 & & & & & & \\
\hline
\end{tabular}

Step 4: Revising Step 2 again by using the idea of IVTSFBM, IVTSFWBM, IVTSFGBM, and IVTSFWGBMO to aggregate the decision matrix is discussed in the form of Table 5.

Table 5. Aggregated matrix by using the information in Table 4 .

\begin{tabular}{|c|c|c|c|c|c|c|}
\hline \multicolumn{7}{|c|}{ IVTSFWBM Operator } \\
\hline & \multicolumn{2}{|c|}{ MD } & \multicolumn{2}{|c|}{ AD } & \multicolumn{2}{|c|}{ NMD } \\
\hline$\breve{w}_{1}^{\breve{\mathcal{A}}}$ & 0.105623495 & 0.166808371 & 0.773199 & 0.867565 & 0.773199 & 0.881319 \\
\hline$\stackrel{\breve{A}}{2}_{2}^{\breve{A}_{2}}$ & 0.121483 & 0.188951 & 0.777927 & 0.853653 & 0.777927 & 0.874731 \\
\hline$\breve{\mathcal{A}}_{3}$ & 0.12076 & 0.193618 & 0.772506 & 0.848133 & 0.772506 & 0.87554 \\
\hline$\breve{\mathcal{A}}_{4}$ & 0.124136 & 0.189602 & 0.796741 & 0.847467 & 0.796741 & 0.894753 \\
\hline$\breve{\mathcal{A}}_{5}^{\breve{A}_{5}}$ & 0.133005 & 0.192158 & 0.795447 & 0.852064 & 0.795447 & 0.885573 \\
\hline
\end{tabular}


Table 5. Cont.

\begin{tabular}{|c|c|c|c|c|c|c|}
\hline \multicolumn{7}{|c|}{ IVTSFWGBM Operator } \\
\hline & \multicolumn{2}{|c|}{ MD } & \multicolumn{2}{|c|}{$\mathrm{AD}$} & \multicolumn{2}{|c|}{ NMD } \\
\hline$\stackrel{\breve{w}}{\mathcal{A}}_{1}$ & 0.686465132 & 0.790641369 & 0.162067 & 0.238226 & 0.163385 & 0.231158 \\
\hline$\breve{w}_{2}^{\breve{A}_{2}}$ & 0.715817 & 0.816414 & 0.168288 & 0.226798 & 0.165558 & 0.22834 \\
\hline$\breve{w}_{3}^{\breve{\mathcal{A}}}$ & 0.702768 & 0.822932 & 0.163966 & 0.219906 & 0.160163 & 0.223403 \\
\hline$\stackrel{\mathcal{A}}{4}_{4}$ & 0.703713 & 0.819731 & 0.17521 & 0.221507 & 0.169188 & 0.22639 \\
\hline 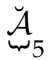 & 0.72389 & 0.814087 & 0.178004 & 0.224763 & 0.173431 & 0.230376 \\
\hline
\end{tabular}

Step 5: Both the using of the concept score functions and the examining of the score values of the aggregated values of Step 3 are discussed in the form of Table 6.

Table 6. Score values of the aggregated values in Table 5.

\begin{tabular}{cccc}
\hline \multicolumn{2}{c}{ IVTSFWBM Operator } & \multicolumn{2}{c}{ IVTSFWGBM Operator } \\
\hline$\breve{\mathcal{A}}_{1}$ & -0.00049255 & $\breve{\mathcal{A}}_{1}$ & 0.267384062 \\
\hline$\breve{\mathcal{A}}_{2}$ & -0.00062 & $\breve{\mathcal{A}}_{2}$ & 0.298235 \\
\hline$\breve{\mathcal{A}}_{3}$ & -0.00063 & $\breve{\mathcal{A}}_{3}$ & 0.296431 \\
\hline$\breve{\mathcal{A}}_{4}$ & -0.00075 & $\breve{\mathcal{A}}_{4}$ & 0.294457 \\
\hline$\breve{\mathcal{A}}_{5}$ & -0.00075 & $\breve{\mathcal{W}}_{5}$ & 0.300672 \\
\hline
\end{tabular}

The graphical expressions of the information in Table 6 are discussed in the form of Figure 1.

\section{Geometrical expression of score values}

0.350000000000000

0.300000000000000

0.250000000000000

0.200000000000000

0.150000000000000

0.100000000000000

0.050000000000000

0.000000000000000

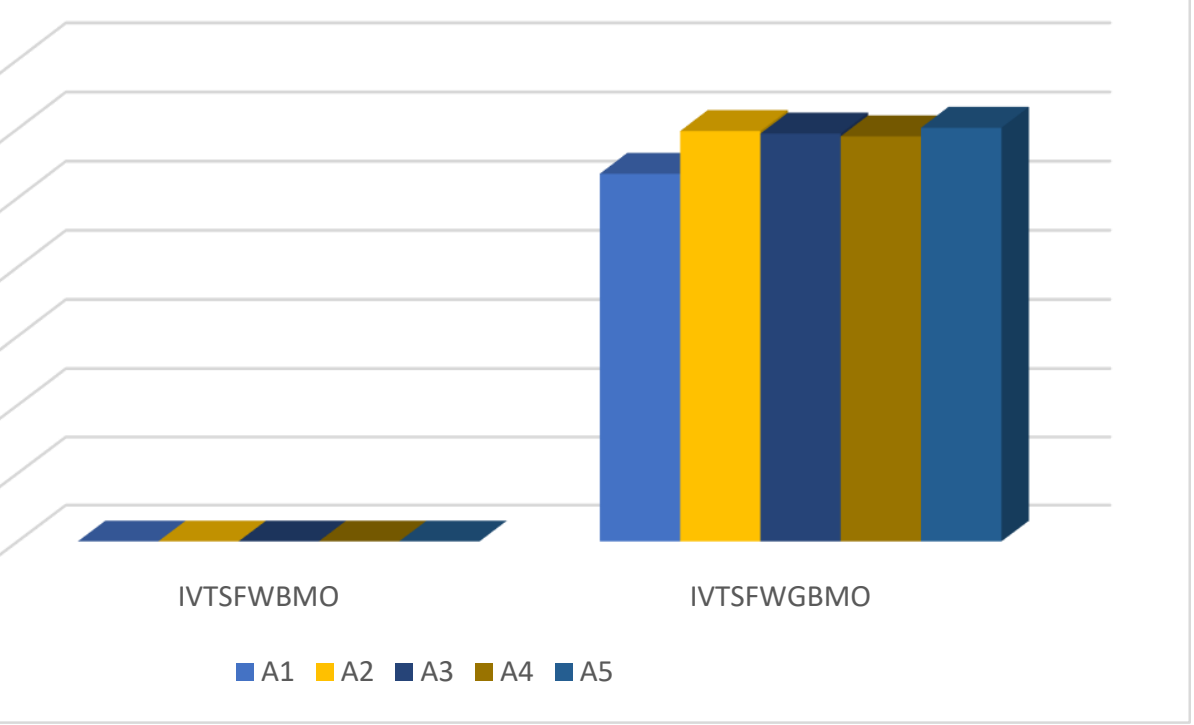

Figure 1. Illustration of the information in Table 6.

By using the information in Table 5, the geometrical expression is discussed in the form of Figure 1. 
Step 6: By using the score values, we rank the all-score values and examine the best one in the form of Table 7.

Table 7. Ranking values of the score values in Table 6.

\begin{tabular}{|c|c|}
\hline Methods & Ranking Values \\
\hline IVTSFWBMO & 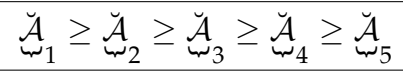 \\
\hline IVTSFWGBMO & 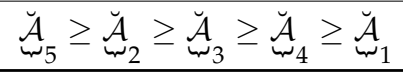 \\
\hline
\end{tabular}

As shown above, the best optimal is $\breve{w}_{1}$ by using the IVTSFWBMO and it is $\breve{w}_{5}$ by using IVTSFWGBMO. Note that the choice of the operator is up to the decision maker and the results using both BM operators may vary. Furthermore, these results are more reliable in comparison to the results obtained using traditional AOs because of the property of the connection of input arguments using the BM operators. Further details about the reliability of the proposed approach is discussed in the next section.

\section{Comparative Analysis}

Many mathematicians used a different kind of theory in the field of MAGDM to find the capability and validity of the analyzed approaches. In this research paper, we utilized the principle of T-spherical fuzzy information through these concepts, which can be usefully applied in the field of weighted and geometric Bonferroni mean operators. Moreover, through the information in Table 4, we can find the capability of the analyzed operators with certain dominant concepts which belong to IVTSFSs. The information above dominant operators are mentioned as follows: AOs of IVTSFWA, IVTSFWG, INVTSFDWA, IVTSFDWG, IFBMO, qROFBMO, GBMO, and PFBMO failed to deal with IVTSF, in which triplets are not defined in the term of crisp numbers. Ullah et al. presented the idea of IVTSFWA, IVTSFWG, IVTSFDWA, and IVTSFDWG operators [45,46]. Xu et al. [47] elaborated the IFBM mean operators for IVTSFSs. Liu et al. [48] initiated the qROFB mean operators for IVTSFSs. Li et al. [49] developed the GB mean operators by using the IVTSFSs and Liang et al. gave the idea of the PFB mean operator. The comparative analysis between the proposed operators and certain prevailing operators is discussed in the form of Table 8 .

Table 8. Comparative analysis of the proposed and existing operators by using the information in Table 4.

\begin{tabular}{|c|c|c|}
\hline Methods & Operator & Ranking Values \\
\hline Proposed & IVTSFWBMO & 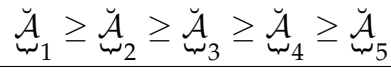 \\
\hline Proposed & IVTSFWGBMO & 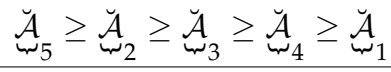 \\
\hline Ullah et al. [50] & IVTSFWA & $\breve{\omega}_{3}^{\breve{\mathcal{A}}} \geq \underset{\omega_{5}}{\breve{\mathcal{A}}} \geq \underset{\omega_{4}}{\breve{\mathcal{A}}} \geq \underset{\omega_{2}}{\breve{\mathcal{A}}} \geq \underset{\omega_{1}}{\breve{\mathcal{A}}}$ \\
\hline Ullah et al. [50] & IVTSFWG & 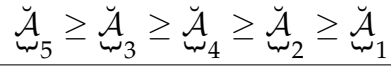 \\
\hline Ullah et al. [51] & IVTSFDWA & 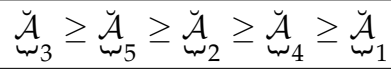 \\
\hline Ullah et al. [51] & IVTSFDWG & $\underbrace{\breve{\mathcal{A}}_{1}}_{\omega_{5}} \geq \underset{\omega_{2}}{\breve{\mathcal{A}}_{2}} \geq{\underset{\omega}{4}}_{\breve{\mathcal{A}}_{4}}^{\breve{\mathcal{A}}_{3}} \geq \underbrace{\breve{\mathcal{A}}_{1}}_{\omega_{1}}$ \\
\hline $\begin{array}{c}\text { Xu and Yager [45] } \\
\text { Xia et al. [47] }\end{array}$ & IFBMO & Failed \\
\hline Liu and Liu [46] & QROFBMO & Failed \\
\hline Liang et al. [48] & PyFBMO & Failed \\
\hline
\end{tabular}

The graphical expressions of the information in Table 8 are discussed in the form of Figure 2. 


\section{comparison of the proposed and existing work}

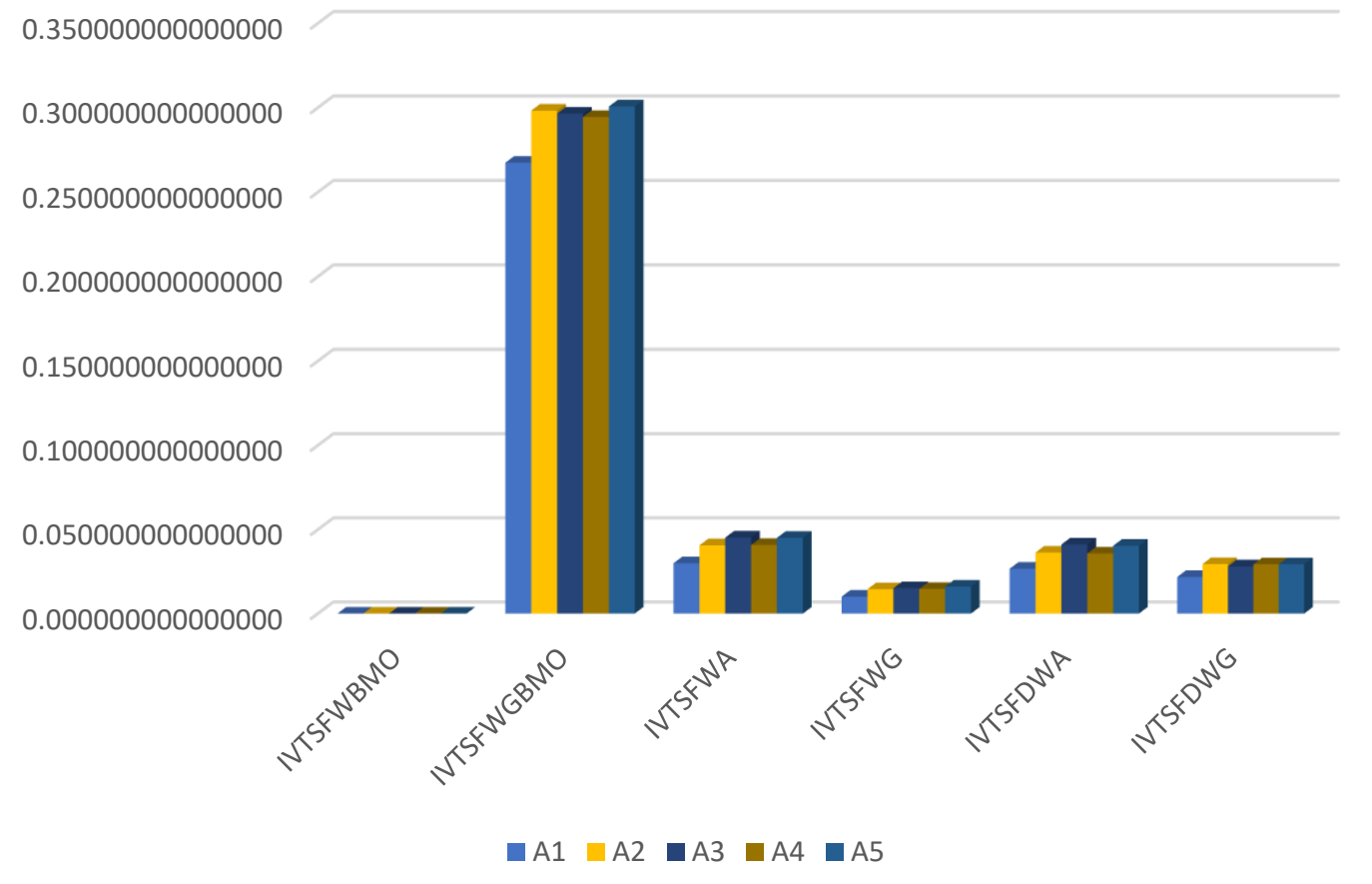

Figure 2. Illustration of the information in Table 8.

\section{Conclusions}

In this article, we studied the BM operators using IVTSF information to cope with MAGDM problems. The main achievements of the paper are as follows.

1. We obtained the IVTSFBM operator by using the algebraic operations of IVTSFNs and the BMs.

2. We discussed the case where the information has weights and proposed IVTSFWBM operators.

3. We determined that the proposed BM operators satisfied the basic properties of aggregation including idempotency, monotonicity, and boundedness.

4. We applied the work to a case study of an energy problem to discuss the efficiency of solar energy cells by using the algorithm of MAGDM with known weights.

5. The advantage of using IVTSFN concerns capturing uncertain information using four kinds of degrees, which helps in reducing information loss and the results obtained become reliable.

6. The proposed BM operators become inapplicable in a scenario when the information has four aspects but each aspect has another further two aspects. In such cases, we need to apply the frame of complex SFSs and complex TSFSs [58].

The frame of IVTSFSs can also be utilized in control systems [59,60]. Furthermore, the BM operators of IVTSFNs can also be accompanied by several other decision-making methods including the VIKOR method [61], TOPSIS method [62,63], CoCoSo method [64], and MABAC method [65].

Author Contributions: Conceptualization, M.A. and K.U.; methodology, M.A. and D.P; software, K.U.; validation, M.A., K.U. and D.P.; formal analysis, D.P.; investigation, M.A., K.U. and D.P. writing-original draft preparation, M.A. and K.U.; writing-review and editing, M.A., K.U. and D.P.; visualization, M.A.; supervision, D.P. funding acquisition, K.U. and D.P. All authors have read and agreed to the published version of the manuscript. 
Funding: This research paper received no external funding.

Institutional Review Board Statement: Not applicable.

Informed Consent Statement: Not applicable.

Acknowledgments: This research study is supported by the office of Research, Innovation, and Commercialization (ORIC) of Riphah International University under the project: Riphah-ORIC-2122/FEAS-20.

Conflicts of Interest: The authors declare no conflict of interest.

\section{References}

1. Zadeh, L.A. Fuzzy sets. Inf. Control 1965, 8, 338-353. [CrossRef]

2. Atanassov, K. Intuitionistic fuzzy sets. Fuzzy Sets Syst. 1986, 20, 87-96. [CrossRef]

3. Garg, H.; Rani, D. Complex interval-valued intuitionistic fuzzy sets and their aggregation operators. Fundam. Inform. 2019, 164, 61-101. [CrossRef]

4. Garg, H.; Rani, D. Novel aggregation operators and ranking method for complex intuitionistic fuzzy sets and their applications to decision-making process. Artif. Intell. Rev. 2019, 1-26. [CrossRef]

5. Garg, H.; Kumar, K. Linguistic interval-valued Atanassov intuitionistic fuzzy sets and their applications to group decision making problems. IEEE Trans. Fuzzy Syst. 2019, 27, 2302-2311. [CrossRef]

6. Yager, R.R. Pythagorean fuzzy subsets. In Proceedings of the Joint IFSA World Congress and NAFIPS Annual Meeting (IFSA/NAFIPS), Edmonton, AB, Canada, 24-28 June 2013; pp. 57-61. [CrossRef]

7. Ali, Z.; Mahmood, T.; Ullah, K.; Khan, Q. Einstein Geometric Aggregation Operators using a Novel Complex Interval-valued Pythagorean Fuzzy Setting with Application in Green Supplier Chain Management. Rep. Mech. Eng. 2021, 2, 105-134. [CrossRef]

8. Garg, H. A linear programming method based on an improved score function for interval-valued Pythagorean fuzzy numbers and its application to decision-making. Int. J. Uncertain. Fuzziness Knowl.-Based Syst. 2018, 26, 67-80. [CrossRef]

9. Mahmood, T. A novel approach towards bipolar soft sets and their applications. J. Math. 2020, 2020, 1-11. [CrossRef]

10. Jan, N.; Aslam, M.; Ullah, K.; Mahmood, T.; Wang, J. An approach towards decision making and shortest path problems using the concepts of interval-valued Pythagorean fuzzy information. Int. J. Intell. Syst. 2019, 34, 2403-2428. [CrossRef]

11. Yager, R.R. Generalized orthopair fuzzy sets. IEEE Trans. Fuzzy Syst. 2016, 25, 1222-1230. [CrossRef]

12. Liu, D.; Chen, X.; Peng, D. Some cosine similarity measures and distance measures between q-rung orthopair fuzzy sets. Int. J. Intell. Syst. 2019, 34, 1572-1587. [CrossRef]

13. Garg, H.; Chen, S.M. Multi attribute group decision making based on neutrality aggregation operators of q-rung orthopair fuzzy sets. Inf. Sci. 2020, 517, 427-447. [CrossRef]

14. Wei, G.; Gao, H.; Wei, Y. Some q-rung orthopair fuzzy Heronian mean operators in multiple attribute decision making. Int. J. Intell. Syst. 2018, 33, 1426-1458. [CrossRef]

15. Talukdar, P.; Goala, S.; Dutta, P.; Limboo, B. Fuzzy multicriteria decision making in medical diagnosis using an advanced distance measure on linguistic Pythagorean fuzzy sets. Ann. Optim. Theory Pract. 2020, 3, 113-131.

16. Zeng, S.; Hu, Y.; Xie, X. Q-rung orthopair fuzzy weighted induced logarithmic distance measures and their application in multiple attribute decision making. Eng. Appl. Artif. Intell. 2021, 100, 104167. [CrossRef]

17. Cuong, B.C. Picture fuzzy sets. J. Comput. Sci. Cybern. 2013, 30, 409-420.

18. Riaz, M.; Çagman, N.; Wali, N.; Mushtaq, A. Certain properties of soft multi-set topology with applications in multi-criteria decision making. Decis. Mak. Appl. Manag. Eng. 2020, 3, 70-96. [CrossRef]

19. Ullah, K. Picture fuzzy maclaurin symmetric mean operators and their applications in solving multiattribute decision-making problems. Math. Probl. Eng. 2021, 2021. [CrossRef]

20. Sahu, R.; Dash, S.R.; Das, S. Career selection of students using hybridized distance measure based on picture fuzzy set and rough set theory. Decis. Mak. Appl. Manag. Eng. 2021, 4, 104-126. [CrossRef]

21. Alshammari, I.; Mani, P.; Ozel, C.; Garg, H. Multiple Attribute Decision Making Algorithm via Picture Fuzzy Nano Topological Spaces. Symmetry 2021, 13, 69. [CrossRef]

22. Mahmood, T.; Ullah, K.; Khan, Q.; Jan, N. An approach toward decision-making and medical diagnosis problems using the concept of spherical fuzzy sets. Neural Comput. Appl. 2019, 31, 7041-7053. [CrossRef]

23. Mahmood, T.; Ullah, K.; Jan, N.; Ahmad, Z. Policy Decision Making Based on Some Averaging Aggregation Operators of T-Spherical Fuzzy Sets; A Multi-Attribute Decision Making Approach. Ann. Optim. Theory Pract. 2020, 3, $69-92$.

24. Jin, Y.; Kousar, Z.; Ullah, K.; Mahmood, T.; Yapici Pehlivan, N.; Ali, Z. Approach to Multi-Attribute Decision-Making Methods for Performance Evaluation Process Using Interval-Valued T-Spherical Fuzzy Hamacher Aggregation Information. Axioms 2021, 10, 145. [CrossRef]

25. Garg, H.; Munir, M.; Ullah, K.; Mahmood, T.; Jan, N. Algorithm for T-spherical fuzzy multi-attribute decision making based on improved interactive aggregation operators. Symmetry 2018, 10, 670. [CrossRef]

26. Garg, H.; Ullah, K.; Mahmood, T.; Hassan, N.; Jan, N. T-spherical fuzzy power aggregation operators and their applications in multi-attribute decision making. J. Ambient Intell. Humaniz. Comput. 2021, 12, 9067-9080. [CrossRef] 
27. Munir, M.; Kalsoom, H.; Ullah, K.; Mahmood, T.; Chu, Y.M. T-spherical fuzzy Einstein hybrid aggregation operators and their applications in multi-attribute decision making problems. Symmetry 2020, 12, 365. [CrossRef]

28. Ullah, K.; Mahmood, T.; Garg, H. Evaluation of the Performance of Search and Rescue Robots Using T-spherical Fuzzy Hamacher Aggregation Operators. Int. J. Fuzzy Syst. 2020, 22, 570-582. [CrossRef]

29. Ullah, K.; Mahmood, T.; Jan, N. Similarity measures for T-spherical fuzzy sets with applications in pattern recognition. Symmetry 2018, 10, 193. [CrossRef]

30. Zeng, S.; Azam, A.; Ullah, K.; Ali, Z.; Asif, A. A method to solve strategy based decision making problems with logarithmic T-spherical fuzzy aggregation framework. J. Intell. Fuzzy Syst. 2021, 41, 7117-7135. [CrossRef]

31. Liu, P.; Khan, Q.; Mahmood, T.; Hassan, N. T-spherical fuzzy power Muirhead mean operator based on novel operational laws and their application in multi-attribute group decision making. IEEE Access 2019, 7, 22613-22632. [CrossRef]

32. Guleria, A.; Bajaj, R.K. T-spherical fuzzy graphs: Operations and applications in various selection processes. Arab. J. Sci. Eng. 2020, 45, 2177-2193. [CrossRef]

33. Guleria, A.; Bajaj, R.K. T-spherical fuzzy soft sets and its aggregation operators with application in decision-making. Sci. Iran. 2021, 28, 1014-1029. [CrossRef]

34. Yager, R.R. The power average operator. IEEE Trans. Syst. Man Cybern.-Part A: Syst. Hum. 2001, 31, 724-731. [CrossRef]

35. Liu, P.; Yu, X. Density aggregation operators based on the intuitionistic trapezoidal fuzzy numbers for multiple attribute decision making. Technol. Econ. Dev. Econ. 2013, 19, 454-470. [CrossRef]

36. Bonferroni, C. Sulle medie multiple di potenze. Boll. Dell'unione Mat. Ital. 1950, 5, 267-270.

37. Sýkora, S. Mathematical means and averages: Generalized Heronian means. Stan's Libr. Castano Primo Italy 2009. [CrossRef]

38. Xu, Z.; Yager, R.R. Intuitionistic fuzzy Bonferroni means. IEEE Trans. Syst. Man Cybern. Part B (Cybern.) 2010, 41, 568-578.

39. Pamucar, D. Normalized weighted geometric Dombi Bonferroni mean operator with interval grey numbers: Application in multicriteria decision making. Rep. Mech. Eng. 2020, 1, 44-52. [CrossRef]

40. Liu, P.; Liu, J. Some q-rung orthopai fuzzy Bonferroni mean operators and their application to multi-attribute group decision making. Int. J. Intell. Syst. 2018, 33, 315-347. [CrossRef]

41. Ateş, F.; Akay, D. Some picture fuzzy Bonferroni mean operators with their application to multicriteria decision making. Int. J. Intell. Syst. 2020, 35, 625-649. [CrossRef]

42. Wei, G. Picture 2-tuple linguistic Bonferroni mean operators and their application to multiple attribute decision making. Int. J. Fuzzy Syst. 2017, 19, 997-1010. [CrossRef]

43. Ali, Z.; Mahmood, T.; Yang, M.S. TOPSIS method based on complex spherical fuzzy sets with Bonferroni mean operators. Mathematics 2020, 8, 1739. [CrossRef]

44. Farrokhizadeh, E.; Shishavan, S.A.S.; Donyatalab, Y.; Gündoğdu, F.K.; Kahraman, C. Spherical fuzzy bonferroni mean aggregation operators and their applications to multiple-attribute decision making. In Decision Making with Spherical Fuzzy Sets; Springer: Cham, Switzerland, 2021; pp. 111-134.

45. Hu, Y.; Zeng, S.; Carlos, L.A.; Ullah, K.; Yang, Y. Social network group decision-making method based on Q-rung Orthopair fuzzy set and its application in the evaluation of online teaching quality. Axioms 2021, 10, 168. [CrossRef]

46. Riaz, M.; Razzaq, A.; Kalsoom, H.; Pamučar, D.; Athar Farid, H.M.; Chu, Y.M. q-Rung orthopair fuzzy geometric aggregation operators based on generalized and group-generalized parameters with application to water loss management. Symmetry $\mathbf{2 0 2 0}$ 12, 1236. [CrossRef]

47. Xia, M.; Xu, Z.; Zhu, B. Geometric Bonferroni means with their application in multi-criteria decision making. Knowl.-Based Syst. 2013, 40, 88-100. [CrossRef]

48. Liang, D.; Zhang, Y.; Xu, Z.; Darko, A.P. Pythagorean fuzzy Bonferroni mean aggregation operator and its accelerative calculating algorithm with the multithreading. Int. J. Intell. Syst. 2018, 33, 615-633. [CrossRef]

49. Yager, R.R. On generalized Bonferroni mean operators for multi-criteria aggregation. Int. J. Approx. Reason. 2009, 50, 1279-1286. [CrossRef]

50. Ullah, K.; Hassan, N.; Mahmood, T.; Jan, N.; Hassan, M. Evaluation of investment policy based on multi-attribute decision-making using interval valued T-spherical fuzzy aggregation operators. Symmetry 2019, 11, 357. [CrossRef]

51. Ullah, K.; Garg, H.; Gul, Z.; Mahmood, T.; Khan, Q.; Ali, Z. Interval Valued T-Spherical Fuzzy Information Aggregation Based on Dombi t-Norm and Dombi t-Conorm for Multi-Attribute Decision Making Problems. Symmetry 2021, 13, 1053. [CrossRef]

52. Riaz, M.; Sałabun, W.; Athar Farid, H.M.; Ali, N.; Wątróbski, J. A robust q-rung orthopair fuzzy information aggregation using Einstein operations with application to sustainable energy planning decision management. Energies 2020, 13, 2155. [CrossRef]

53. Dhiman, H.S.; Deb, D. Fuzzy TOPSIS and fuzzy COPRAS based multi-criteria decision making for hybrid wind farms. Energy 2020, 202, 117755. [CrossRef]

54. Wang, C.N.; Dang, T.T.; Bayer, J. A Two-Stage Multiple Criteria Decision Making for Site Selection of Solar Photovoltaic (PV) Power Plant: A Case Study in Taiwan. IEEE Access 2021, 9, 75509-75525. [CrossRef]

55. Wang, Z.; Li, Y.; Wang, K.; Huang, Z. Environment-adjusted operational performance evaluation of solar photovoltaic power plants: A three stage efficiency analysis. Renew. Sustain. Energy Rev. 2017, 76, 1153-1162. [CrossRef]

56. Erdogan, N.; Pamucar, D.; Kucuksari, S.; Deveci, M. An integrated multi-objective optimization and multi-criteria decision-making model for optimal planning of workplace charging stations. Appl. Energy 2021, 304, 117866. [CrossRef]

57. Ye, Y.; Shang, Y. Finite-time median-related group consensus over directed networks. Int. J. Control 2020, 93, 1485-1498. [CrossRef] 
58. Ali, Z.; Mahmood, T.; Yang, M.-S. Complex T-Spherical Fuzzy Aggregation Operators with Application to Multi-Attribute Decision Making. Symmetry 2020, 12, 1311. [CrossRef]

59. Roman, R.C.; Precup, R.E.; Petriu, E.M. Hybrid data-driven fuzzy active disturbance rejection control for tower crane systems. Eur. J. Control 2021, 58, 373-387. [CrossRef]

60. Zhu, Z.; Pan, Y.; Zhou, Q.; Lu, C. Event-triggered adaptive fuzzy control for stochastic nonlinear systems with unmeasured states and unknown backlash-like hysteresis. IEEE Trans. Fuzzy Syst. 2020, 29, 1273-1283. [CrossRef]

61. Badi, I.; Pamucar, D. Supplier selection for steel making company by using combined Grey-MARCOS methods. Decis. Mak. Appl. Manag. Eng. 2020, 3, 37-48. [CrossRef]

62. Bozanic, D.; Milic, A.; Tešic, D.; Salabun, W.; Pamucar, D. D numbers-FUCOM-Fuzzy RAFSI model for selecting the group of construction machines for enabling mobility. Facta Univ. Ser. Mech. Eng. 2021, 19, 447-471. [CrossRef]

63. Ramakrishnan, K.R.; Chakraborty, S. A cloud TOPSIS model for green supplier selection. Facta Univ. Ser. Mech. Eng. 2020, 18, 375-397. [CrossRef]

64. Biswas, T.; Chatterjee, P.; Choudhuri, B. Selection of commercially available alternative passenger vehicle in automotive environment. Oper. Res. Eng. Sci. Theory Appl. 2020, 3, 16-27. [CrossRef]

65. Pamucar, D.S.; Savin, L.M. Multiple-criteria model for optimal off-road vehicle selection for passenger transportation: BWMCOPRAS model. Mil. Tech. Cour. 2020, 68, 28-64. [CrossRef] 